\title{
Eco-efficient processes for biodiesel production from waste lipids
}

DOI:

10.1016/j.jclepro.2019.118073

\section{Document Version}

Accepted author manuscript

Link to publication record in Manchester Research Explorer

\section{Citation for published version (APA):}

Dimian, A. C., \& Kiss, A. A. (2019). Eco-efficient processes for biodiesel production from waste lipids. Journal of Cleaner Production, 239, [118073]. https://doi.org/10.1016/j.jclepro.2019.118073

\section{Published in:}

Journal of Cleaner Production

\section{Citing this paper}

Please note that where the full-text provided on Manchester Research Explorer is the Author Accepted Manuscript or Proof version this may differ from the final Published version. If citing, it is advised that you check and use the publisher's definitive version.

\section{General rights}

Copyright and moral rights for the publications made accessible in the Research Explorer are retained by the authors and/or other copyright owners and it is a condition of accessing publications that users recognise and abide by the legal requirements associated with these rights.

\section{Takedown policy}

If you believe that this document breaches copyright please refer to the University of Manchester's Takedown Procedures [http://man.ac.uk/04Y6Bo] or contact uml.scholarlycommunications@manchester.ac.uk providing relevant details, so we can investigate your claim.

\section{OPEN ACCESS}




\section{Eco-efficient processes for biodiesel production from waste lipids}

3 Alexandre C. Dimian, ${ }^{1}$ Anton A. Kiss, ${ }^{2,3 *}$

4

\section{Keywords}

\section{Highlights}

\section{Abstract}

${ }^{1}$ University "Politehnica" of Bucharest, Dept. of Chemical and Biochemical Engineering, Faculty of Applied Chemistry and Materials Science, Polizu 1-7, 011061 Bucharest, Romania

${ }^{2}$ School of Chemical Engineering and Analytical Science, The University of Manchester, Sackville Street, Manchester, M13 9PL, United Kingdom

${ }^{3}$ Sustainable Process Technology Group, Faculty of Science and Technology, University of Twente, PO Box 217, 7500 AE Enschede, The Netherlands

*Corresponding author: TonyKiss@gmail.com, Tel: +44 1613068759

FFA treatment; green catalysis; integrated design; process intensification; reactive distillation

- New integrated processes developed for biodiesel production from waste fatty sources

- Effective combination of esterification and transesterification by reactive separations

- Glycerolysis of high FFA feedstock coupled with hetero-catalyzed transesterification

The paper proposes innovative eco-efficient processes for converting waste lipid feedstock with up to $35 \%$ free fatty acids into biodiesel. Free fatty acids pre-treatment is a key issue, which can be handled by esterification with methanol or glycerol, using hetero- or homogeneous catalyst. The integration with the transesterification stage is possible using methods based on process intensification and heterogeneous catalysis. Three integrated continuous processes are investigated. The first performs the esterification with methanol by reactive absorption and superacid solid catalyst, followed by transesterification by reactive distillation with alkali catalyst. The second method applies the esterification with glycerol at high temperature, coupled with transesterification by heterogeneous catalyst in a variable residence-time plug-flow reactor. The third alternative replaces the second reaction stage with vacuum distillation. In all cases, biodiesel fulfills the specifications of D6751 and EN14214 norms. This result is obtained by kinetic simulation of reactors including free fatty acids esterification and glycerides transesterification. A techno-economic analysis pinpoints the pros and cons of each process. The first process is suited for low free fatty acids content, as used cooking oils. The second and third processes can be applied for higher content of free fatty acids, such as animal fats and greases. Particularly the third process can deliver biodiesel of highest quality, conforming to the cold soak filtration test. 


\section{1. Introduction}

2 Biodiesel keeps a prominent place among the renewable biofuels, being a key product of biorefineries based on the oleo-chemicals platform (Kiss et al., 2016). According to UFOP, the global biodiesel production reached about 34 million tons in 2016. European Union is the largest biodiesel producer with 12.6 million tons (37\% of total), having key producers such as Germany (3.1), France (2.0), Spain (1.6), The Netherlands (1.2) and Italy (1). United States, Brazil and Argentina produced 6.2, 3.3 and 2.7 million tons, respectively. Asia produced 5.4 million tons, with key contributors such as Indonesia (3.15), Thailand (1.16) and Singapore (1). China had a modest production of only 0.44 million tons, but it has a very large potential. Biodiesel includes fatty acid methyl esters (FAME) and hydrogenated vegetable oil (HVO). The main resources today are crops of vegetable oils, from which palm oil (37\%), soybean oil (27\%) and rapeseed oil (20\%), followed by used cooking oils (UCO) (10\%), animal fat (7\%) and others (5\%). Rapeseed is about $48 \%$ from feedstock, but the share of UCO and fats raises to $18 \%$. In Germany the use of UCO for biodiesel in 2017 was 1.5 million tons (about half of biodiesel production), which is more than the domestic available rapeseed oil (UFOP, 2017). This work focuses on the valorization of UCO together with waste fats resulting from other food processing, such as poultry and animal fat (tallow, lard). There are several major reasons to promote UCO as a key resource that goes beyond its today share: 1) it avoids pollution of soil and water by wastes that spoil the environment; 2) it is sustained by a positive public opinion of clean production, converting waste into products; and 3) it avoids the food vs fuel controversy. As low-cost feedstock (about half the price of original oil), waste lipids are very economically attractive and more sustainable (Macombe et al., 2013). The problem with using UCO and fats as feedstock is that they have various origin and composition, contain variable fraction of free fatty acids (FFA) and contaminants. Processing waste feedstock into biodiesel requires effective pre-treatment methods that are eco-efficient and preserve the environment against pollution. Employing strong acids and bases should be limited or avoided, while the substantial amounts of water used should be recycled. Using solid catalysts for reactions and adsorption media for purification may greatly simplify the flowsheet and save energy. Process intensification techniques (Chuah et al., 2017) are also useful and should be considered for a cleaner production of biodiesel, for example by reactive separations (Kiss, 2014). Integrating new methods in the design of more eco-efficient processes for converting waste lipids into biodiesel is the goal of this paper. A plant capacity of $20 \mathrm{ktpy}$ is considered, and an upper limit of $15 \%$ wt FFA is assumed when treating UCO, while max. $35 \%$ wt FFA is used when dealing with animal fats or trap (brown) grease. 
1 Many papers explored the use of UCO, animal fats and waste lipids for manufacturing biodiesel, most of them handling physical and chemical aspects regarding the feedstock pretreatment and the conversion to biodiesel by various means. Comprehensive papers and reviews are available, covering topics such as: technical aspects of production and analysis of biodiesel from UCO (Enweremadu and Mbarawa, 2009); technologies for UCO conversion (Math et al., 2010); biodiesel production, properties, and flexible feedstock (Moser, 2009); biodiesel production from high FFA feedstock (Atadashi et al., 2012); conversion of slaughterhouse and poultry farm animal fats and wastes to biodiesel (Chakraborty et al., 2014); intensification approaches for biodiesel synthesis from UCO (Maddikeri et al., 2012); sustainable biodiesel production by waste-oil biodiesel utilization (Hajjari et al., 2017); and a handbook on biodiesel (Knothe et al., 2010).

From the large number of papers, only one refers directly to the full process design and simulation. Zhang et al. (2003a, 2003b) considered a plant capacity of 8,000 tpa with feedstock containing 6\% FFA. The paper claimed that the acid-catalyzed transesterification using UCO proved to be techno-economically viable, but to the best of our knowledge this has not happened so far in the industrial practice, where the alkali-based process remains the most employed. The paper also contains several drawbacks regarding the technology and computer simulation. The plant has a simple black-box unit hence the biodiesel specifications cannot be guaranteed. The plant is designed with unreacted oil recycle, involving deep vacuum distillation of FAME operating in unrealistic conditions.

The waste lipids (WL) feedstock for biodiesel can be characterized by the fatty acid profiles. Table 1 displays typical compositions for UCO, tallow, poultry fat and lard, as well as for palm and sunflower oils whose blends are used the most used as cooking oils. The composition is lumped in five categories: C16:0 (palmitic), C18:0 (stearic), C18:1 (oleic), C18:2 (linoleic), and C18:3 (linolenic). The palmitic category includes all saturated species up to C16:0, while oleic category includes all single double bond species. The applicability of feedstock for biodiesel manufacturing may be characterized by USI index (unsaturated to saturated fatty acids ratio). Feedstock with high content in saturated fatty acids (palm and tallow) has USI close to 1 . Hence the cetane number (which reflects the combustion properties including $\mathrm{NO}_{\mathrm{x}}, \mathrm{PM}, \mathrm{HC}$ and $\mathrm{CO}$ ) has high values, but problems may rise during the cold weather. Sunflower oil has most unsaturated TG and is therefore better suited for colder weather, but this profile is unfavorable from the viewpoint of oxidation stability and storage. The FFA content of waste lipids is very variable, and a distinction may be made between UCO and animal fats. UCO has an FFA content of $2-10 \%$, the lower bound being typical for countries with 
1 rigorous public health rules, e.g. 3\% in The Netherlands (Venkatesh et al., 2014). For animal fats and trap grease residues, the FFA content is typically larger than $15 \%$ wt (Tu at al., 2017). This large variation is a challenge when designing biodiesel plants processing waste lipids, being in contrast with processes handling vegetable crops oils of almost constant quality. Also, during the cooking process the oil composition suffers a significant but unpredictable variation because of degradation reactions. In general, the saturation degree increases, which affects negatively the viscosity (Knothe and Steidley, 2009). Systematic testing of the feedstock is needed before FFA treatment. The plant should have certain flexibility in terms of FFA processing, but also in the transesterification stage. Alternatively, in view of maintaining the operation conditions, blends of feedstock may be envisaged (waste fats and vegetable oils), adapted to local market conditions.

Based on the fatty acid profile, a design of biodiesel properties may be undertaken for a specific application by considering only five fundamental fatty acids, as indicated in Table 1 (Knothe, 2008, 2010). The cetane number varies in the series of C18 FAME as following: stearate (101), oleate (56), linoleate (38) and linolenate (22.7). Hence the interest is maximizing the content in saturated esters (which also improve stability to oxidation). But in case of the melting point (which translates into cold weather properties) the $\mathrm{C} 18$ variation is: $39,-19.5,-35$ and $-52{ }^{\circ} \mathrm{C}$. Hence more unsaturated esters are preferred for cold weather usage. Design of biodiesel properties should find the best compromise, and this is the case when the feedstock has 60-70\% wt oleic acid esters.

\section{Approach and originality}

This paper provides innovative conceptual design of integrated processes for converting waste lipid feedstock into biodiesel. A plant capacity of $20 \mathrm{ktpy}$ is considered. The feedstock can be UCO with an upper limit of $15 \%$ wt FFA, as well as animal fats, oils and (trap) greases (FOG), while max. $35 \%$ wt FFA is assumed.

A key issue is the FFA pre-treatment stage. This is handled by esterification with methanol or glycerol. It is shown that the esterification with methanol by reactive absorption using superacid solid catalyst (ion-exchange resin Amberlyst-15, thermally stable up to $150^{\circ} \mathrm{C}$ ) is particularly effective offering flexibility up to FFA $15 \%$ wt just by adjusting the operation conditions (e.g. amount of methanol or column's pressure). A second alternative, which can be applied for handling FOG feedstock, is the autocatalytic esterification with glycerol at high temperature, compatible the transesterification employing solid base catalysts.

The process synthesis approach used in this work handles the integration of three stages: pretreatment, transesterification and post-treatment. Using a suitable catalyst plays an essential role in technology. The final goal of the design is the fulfillment of quality specifications of 
1 biodiesel, as defined by the norms EN14214 and ASTM D6751, which was upgraded in 2008 2 to include the cold soak filtration test (Van Gerpen, 2017a).

3 A distinct feature of this paper is the use of detailed kinetic modeling for simulating chemical reactors, both for FFA esterification and transesterification, such that the final product respects the quality specifications required by the norms. This approach regards particularly the "bound-glycerol" that includes residual TG, DG, MG, and free glycerol, as well as the "acid value" due to the residual FFA. For this reason, the process design adopts as general strategy a two-stage transesterification with intermediate glycerol removal which guarantees the fulfillment of specifications. When applying only one-stage transesterification - by heterogeneous catalyst and very high conversion - the vacuum distillation is applied in view of obtaining high-quality biodiesel that satisfies the cold-soak test. The selection of the operation parameters (pressure, temperature profile, reflux ratio, bottom flowrate and composition) and the column's design considers the risk of product degradation and the use of an appropriate utility for heating.

Several design alternatives emerge that are discerned both by the FFA pre-treatment method as well as by the catalyst employed in the transesterification stage. The flowsheets of these process alternatives are original, and to the best of our knowledge have not been proposed so far in the literature.

Process 1 uses homogeneous alkali catalyst (current standard) for transesterification, with intermediate glycerol removal that ensures the biodiesel specifications at the reaction stage. The best FFA pre-treatment method is esterification with methanol in a continuous reactive absorption setup using a superacid ion-exchange catalyst. The transesterification stage uses a CSTR-PFR tandem, followed by a reactive distillation (RD) for the second stage.

Process 2 employs as FFA pre-treatment stage the esterification with glycerol at $250{ }^{\circ} \mathrm{C}$. This approach allows direct coupling with transesterification using a heterogeneous base catalyst at high temperature. An innovative reactor design offers a large flexibility in operation, by a variable-time construction and easy catalyst replacement. The result is a compact equipment and energy efficient process.

29 Process 3 is based on similar conceptual ideas, but it uses separation by vacuum distillation for recycling unconverted material and delivering high-quality product. By suppressing the second trans-esterification stage, the flowsheet becomes even simpler. Attention is given to the simulation and design of the biodiesel distillation, by respecting the temperature constraint of the reboiler bellow $280{ }^{\circ} \mathrm{C}$. The need of recycling substantial amounts of FAME and mono- 
1 glycerides is highlighted. This process has a good potential for application dealing with high 2 FFA feedstock.

3 With respect to post-treatment, this work highlights the post-processing method suitable for each alternative. Water washing is favored when dealing with alkali catalysis, while dry wash treating of biodiesel by heterogeneous catalysis is perfectly suitable. In addition, the glycerol co-product is of high purity. The economic evaluation indicates that the capital costs are equivalent for the three processes, although for different reasons. The energy requirements and $\mathrm{CO}_{2}$ emissions are low. Suitable recommendations are formulated for process selection.

\section{Process design and simulation}

This section provides details about the property models required for simulation, the reaction schemes and kinetics, as well as characteristics of the feedstock (waste lipids).

\subsection{Physical property models}

The physical properties required for simulation and the binary interaction parameters were available for pure components in the Aspen Plus v9.0 database, while the other interaction parameters were estimated using UNIFAC - Dortmund modified group contribution method (Gmehling et al., 2002). In the case of methanol-water separation there is only one liquid (aqueous) phase possible, while for the liquid-liquid separation by decanting, the UNIFACDortmund model was applied.

\subsection{Reaction scheme and kinetics}

This section provides the reaction schemes for the FFA pre-treatment and transesterification of triglycerides, along with the pseudo-homogeneous and heterogeneous kinetics.

\subsubsection{FFA pre-treatment}

The free fatty acids (FFA) pretreatment step relies on two methods. The first consists of esterification with methanol:

$\mathrm{FFA}+\mathrm{MeOH} \rightleftharpoons \mathrm{FAME}+\mathrm{H}_{2} \mathrm{O}$

30 The acid-type catalyst may be a mineral acid, mostly sulfuric acid, or heterogeneous, usually

31 ion-exchange resins. This topic was recently analysed by Chai et al. (2014) including kinetic 32 aspects. In this study we prefer the use of heterogeneous catalysis. Kinetic data for using 33 Amberlyst 15 resin were published by Steingeweg and Gmehling (2003). They studied this 
1 reaction in a laboratory column equipped with structured packing Katapak-SP. The model 2 considers the reversible reaction:

3 Acid + Alcohol $\rightleftharpoons$ Ester + Water

4 Two kinetic models were proposed: pseudo-homogeneous and LHHW heterogeneous. The rate equation for the pseudo-homogeneous model is:

$6 \quad \mathrm{r}_{\mathrm{Ac}}=-\mathrm{dN}_{\mathrm{Ad}} / \mathrm{dt}=\mathrm{m}_{\mathrm{cat}} \times\left(\mathrm{k}_{1} \mathrm{a}_{\mathrm{Ac}} \mathrm{a}_{\mathrm{Al}}-\mathrm{k}_{-1} \mathrm{a}_{\mathrm{E}} \mathrm{a}_{\mathrm{W}}\right)$

The concentrations are expressed in terms of activities, which in turn are given by the molar fractions multiplied by activity coefficients. The LHHW model considers the adsorption of different species on heterogeneous catalyst surface. In this case Steinigeweg and Gmehling (2003) demonstrate that only the sorbtion of water is of significance. Accordingly, the wellknown LHHW rate expression can be simplified to the following equation:

$\mathrm{r}_{\mathrm{Ac}}=-\mathrm{dN} \mathrm{N}_{\mathrm{Ac}} / \mathrm{dt}=\mathrm{m}_{\mathrm{cat}} \times\left(\mathrm{k}_{1} \mathrm{a}_{\mathrm{Ac}} \mathrm{a}_{\mathrm{Al}} /\left(\mathrm{K}_{\mathrm{S}} \mathrm{a}_{\mathrm{W}}\right)^{2}-\mathrm{k}_{-1} \mathrm{a}_{\mathrm{E}} /\left(\mathrm{K}_{\mathrm{S}} \mathrm{a}_{\mathrm{W}}\right)\right)$

13 in which $\mathrm{K}_{\mathrm{S}}$ is a sorbtion constant. Table 2 presents the parameters of the model. According the above reference the homogeneous model gives a slight overestimation of the reaction rate by $10-15 \%$. Note that Aspen Plus cannot consider LHHW kinetics in a reactive distillation process but can well include power-law kinetics. Accordingly, equation (4) may be applied. However, the initial feed should contain some water to avoid numerical problems because of the hyperbolic form of the equation (4). The second FFA esterification method employs glycerol, this time a heavy alcohol. The FFAs are converted in glycerides that join the flow sent to transesterification. First MGs are formed, further converted to di- and triglycerides:

$\mathrm{GLY}+\mathrm{FFA} \rightleftharpoons \mathrm{MG}+\mathrm{H}_{2} \mathrm{O} ; \quad \mathrm{MG}+\mathrm{FFA} \rightleftharpoons \mathrm{DG}+\mathrm{H}_{2} \mathrm{O}$

$\mathrm{DG}+\mathrm{FFA} \rightleftharpoons \mathrm{TG}+\mathrm{H}_{2} \mathrm{O}$

After water removal by evaporation, the TG and DG are converted back to MG:

$\mathrm{TG}+\mathrm{GLY} \rightleftharpoons \mathrm{DG}+\mathrm{MG} ; \quad \mathrm{DG}+\mathrm{GLY} \rightleftharpoons \mathrm{MG}$

The reaction can be catalyzed by strong mineral acids, as well as by some heavy metal salts. Recently, Tu et al. (2017) found that at temperatures over $200{ }^{\circ} \mathrm{C}$ the reaction becomes autocatalytic. They reported first-order kinetics with $\mathrm{k}=1.445 \mathrm{~h}^{-1}$ at $230{ }^{\circ} \mathrm{C}$ and activation energy $E_{a}=69.14 \mathrm{~kJ} / \mathrm{mol}$. Accordingly, the pre-exponential factor is $\mathrm{k}=2.18 \times 10^{7} \mathrm{~h}^{-1}$.

\subsubsection{Transesterification of triglycerides}

31 The chemistry of the transesterification with methanol involves several reactions that convert triglycerides (TG), diglycerides (DG), and monoglycerides (MG) to fatty acid methyl esters (FAME) and glycerol (GLY), as follows: 
$1 \quad \mathrm{TG}+\mathrm{MeOH} \rightleftharpoons \mathrm{DG}+\mathrm{FAME}$

$2 \mathrm{DG}+\mathrm{MeOH} \rightleftharpoons \mathrm{MG}+\mathrm{FAME}$

$3 \quad \mathrm{MG}+\mathrm{MeOH} \rightleftharpoons \mathrm{GLY}+\mathrm{FAME}$

The free fatty acids (FFA) pretreatment step relies on the esterification with methanol:

$6 \quad \mathrm{FFA}+\mathrm{MeOH} \rightleftharpoons \mathrm{FAME}+\mathrm{H}_{2} \mathrm{O}$

The reaction medium by transesterification is actually a very fine dispersion consisting of two-liquid phases. Because of vigorous agitation in the first minutes of contact and the formation of tension-active species (mono- and di-glycerides), the liquid mixture may be considered as pseudo-homogeneous emulsion. Therefore, the mass transfer did not influence the process kinetics. Moreover, the kinetic data used in this work (Bambase et al., 2007; Allain et al., 2016) were obtained by using this realistic assumption. For the same reasons, the reactive distillation columns are simulated by using VLE and not VLLE. Property constant estimation system (PCES) was used to generate the parameters of the thermophysical models of tri- di- and mono-glycerides that were missing from the Aspen Plus database.

Kinetics for transesterification by homogeneous catalysis. For the homogeneous catalysis it is appropriate to apply the detailed kinetic model of Bambase et al. (2007) who studied the trans-esterification of sunflower with $\mathrm{NaOH}$ catalyst $0.5 \% \mathrm{wt} /$ oil. The kinetic parameters are summarized in Table 3. The equilibrium constants indicate that the first and third reactions are strongly oriented to the formation of products, while for the second reaction is more balanced, with the result of controlling the final biodiesel composition. A question may rise if the above model is compatible with the fatty acid profiles of the UCO and fats and if conceivable differences in the kinetic behavior of species would affect the results. This issue was found indeed to be important in heterogeneous catalysis (Dimian et al., 2010) resulting in significant difference in the triglycerides conversion and the product specifications (Dimian and Rothenberg, 2016). However, when dealing with homogeneous catalysis in well-mixed reactors such differences are improbable, since the steric and bond effects should not play a role. The composition of initial oil and final product are identical in term of fatty acid composition, which is a good indication that there are no noteworthy differences in the reaction rate of species (Chang and Liu, 2010).

32 A key merit of the kinetic model from Bambase et al. (2007) is the ability of predicting the formation of a significant amount of MG vs DG in the final product, as indicated by the 
1 EN14214 norm (0.80 vs. 0.20\%wt). Other models that might be employed (Nurreddini, 1997;

Vincente, 2005) have the drawback of predicting the formation of more DG than MG. Likozar and Levec (2014) developed a comprehensive analysis of transesterification by alkali catalyst, and determined by regression the kinetic parameters (pre-exponential factors and activation energy) of the individual fatty acid species involved (e.g. stearic, oleic, linoleic, linolenic). When combined with the fragment-based approach for estimating thermophysical properties of fatty acids and derived molecules (Zong et al., 2010), this method would allow the prediction of key biodiesel properties (density, viscosity, flash point, cetane number) based on the initial feedstock composition only (Chang and Liu, 2010). However, the kinetic parameters listed by Likozar and Levec (2014) have not been validated against other experimental researches. In addition, the kinetic modelling based on species raises another problem, the property estimation of so many molecular species. Thus, the model of Bambase et al. (2007) is considered suitable for designing a reaction system that can realistically achieve the required product quality.

Kinetics for transesterification by heterogeneous catalysis. This work considers the zinc aluminate catalyst developed by the French company AXENS. Table 4 gives the kinetic parameters adapted from Allain et al. (2016). A correction was necessary, since the industrial reactors employ cylindrical pellets of $3.0 \mathrm{~mm}$, while the lab reactor used grains of $0.4 \mathrm{~mm}$. It was assumed considering an overall efficiency of 0.25 that multiplies the pre-exponential factors of the original rate equations. The activation energy is set equal for forward and back reactions, as the global thermal effect of reaction is practically zero. This approach was founded suitable for describing the behavior of industrial reactors dealing with rapeseed-oil type feedstock (Dimian and Rothenberg, 2016). The detailed kinetic models presented have been implemented in Aspen Plus v9.0 by taking the oleic acid as base molecule for the glycerides and the fatty acid methyl ester (FAME). Property constant estimation system (PCES) was used to generate the parameters of the thermo-physical models of the tri- di- and mono-glycerides that were missing from the Aspen Plus database.

\subsection{Technology issues}

Figure 1 displays a block diagram for manufacturing biodiesel from waste lipids. After washing with hot water to remove soluble impurities and filtering, the feedstock is submitted to degumming with hydrophosphoric acid. Additional treatment with chelating agents or adsorbents may be considered for feedstock containing long-chain triglycerides over C20. The 
1 feedstock is then sent to storage in view of blending and FFA treatment. The processing steps include free fatty acid (FFA) pre-treatment, transesterification and post-treatment, briefly examined. This section handles also constraints and design decisions that have been considered for developing the integrated processes proposed in this paper.

\subsubsection{FFA pre-treatment}

The lipid feedstock may contain variable FFA amounts that should be removed or converted to esters before transesterification. Soaps are formed by reaction of FFA with alkali catalyst:

$$
\mathrm{R}_{1}-\mathrm{COOH}+\mathrm{NaOH} \rightarrow \mathrm{R}_{1}-\mathrm{COONa}+\mathrm{H}_{2} \mathrm{O}
$$

Another undesired reaction is the saponification of dissolved ester in the glycerol phase:

$\mathrm{R}_{1}-\mathrm{COO}-\mathrm{CH}_{3}+\mathrm{NaOH} \rightarrow \mathrm{R}_{1}-\mathrm{COONa}+\mathrm{CH}_{3} \mathrm{OH}$

The soaps that cause foaming can be removed by filtering, although the reconversion to FFA by treatment with mineral acid is the preferred method:

$\mathrm{R}_{1}-\mathrm{COONa}+$ acid $\rightarrow \mathrm{R}_{1}-\mathrm{COOH}+$ salt

The target of FFA reduction in industry is below $2 \mathrm{mg} \mathrm{KOH} / \mathrm{g}$ or $0.5-1 \%$ with respect to oil. The water content should be below $0.1 \%$ wt, but better below 500 ppm. For an FFA range of 1-2 \%wt the problem is solved usually by increasing the amount of base catalyst for transesterification. When the FFA amount exceeds $2 \% \mathrm{wt}$ the oil pre-treatment is compulsory. This can follow two methods: caustic stripping or esterification with suitable alcohol. By the first method the FFA are converted in soaps by alkali treatment followed by removal. By the second method the FFA are transformed to esters that remain in the biodiesel. This is more advantageous from an economical viewpoint.

When methanol is used for transesterification, FFAs are converted directly in FAME. The amount of chemicals and pre-treatment time may be determined based on FFA analysis. The recommendation by US-NREL agency is 20:1 methanol-to-FFA molar ratio and 5\% wt. $\mathrm{H}_{2} \mathrm{SO}_{4}$-to FFA, as well as 2 hours reaction time (Van Gerpen et al., 2004). Chai et al. (2014) re-examined this rule and found that it works well at higher FFA content (above $15 \%$ wt.), but for lower FFA content - as encountered with UCO - the methanol-to- FFA molar ratio should be increased to $40: 1$ and the catalyst amount to $10 \%$ wt to FFA, for temperatures of $55-65{ }^{\circ} \mathrm{C}$. When glycerol is employed as alcohol for esterification, the FFA is converted in glycerides that are then transesterified. First MGs are formed, further converted to di- and triglycerides:

$\mathrm{GLY}+\mathrm{FFA} \rightleftharpoons \mathrm{MG}+\mathrm{H}_{2} \mathrm{O} ; \quad \mathrm{MG}+\mathrm{FFA} \rightleftharpoons \mathrm{DG}+\mathrm{H}_{2} \mathrm{O} ; \quad \mathrm{DG}+\mathrm{FFA} \rightleftharpoons \mathrm{TG}+\mathrm{H}_{2} \mathrm{O}$

After water removal by evaporation, the TG and DG are converted back to MG: 
$1 \quad \mathrm{TG}+\mathrm{GLY} \rightleftharpoons \mathrm{DG}+\mathrm{MG} ; \quad \mathrm{DG}+\mathrm{GLY} \rightleftharpoons \mathrm{MG}$

2 The esterification with glycerol takes place at higher temperatures (over $150{ }^{\circ} \mathrm{C}$ ) but normal pressure. The water is easy removed by evaporation. The presence of mono-glycerides has as positive effect an increased solubility of methanol in the oil phase and the stabilization of the liquid-liquid dispersion. This method is particularly suitable for treating fats, oils and greases (FOG) feedstock with high FFA content, over $15 \%$ wt (Wang et al., 2012). Both homogeneous and heterogeneous catalysts have been considered. Venkatesh et al. (2014) found that by treatment with $3 \%$ wt. $\mathrm{H}_{2} \mathrm{SO}_{4}$ at $150{ }^{\circ} \mathrm{C}$ the FFA content of industrial FOG drops by $90 \%$ in less than 2 hours in a batch reactor. On the contrary, at the same temperature using sulfated zirconia catalyst needs much more time. Felizardo et al. (2011) used Zn acetate at temperatures in the range of $180-230{ }^{\circ} \mathrm{C}$ and glycerol excess of 4 to $65 \%$. The best conditions were with $0.1 \%$ wt catalyst at $220{ }^{\circ} \mathrm{C}, 10 \%$ glycerol excess and $500 \mathrm{rpm}$ stirring rate, when the FFA conversion was $94.7 \%$ in 60 minutes; while 120 minutes were necessary without catalyst, for the same result.

At temperatures over $200{ }^{\circ} \mathrm{C}$ the esterification with glycerol becomes autocatalytic. Tu et al. (2017) found that this may be successfully applied for treating FOG with 30\% FFA to reduce it to $1 \%$. At 1:1 molar ratio, the optimal conditions in a batch reactor were $230{ }^{\circ} \mathrm{C}$ and 150 minutes. The important result for this study is that FFA pre-treatment may be compatible with the transesterification by heterogeneous catalyst that takes place at the same temperature level. The result is significant flowsheet simplification and energy saving.

\subsubsection{Transesterification}

In the second stage, the FFA-free stream is sent to the main processing stage, the transesterification with methanol to produce FAME, using hetero- or homogeneous base catalysts. The reaction must run practically at full conversion aiming for the lowest possible amounts in MG and DG. The European EN 14421 norm limits the content of TG to $0.2 \%$ wt, DG 0.2 \%wt and MG $0.8 \%$ wt. In the US ASTM standard D6751 these requirements are lumped into a single specification, the 'bound glycerol' that must be below $0.2 \%$ wt This specification is considered the most important (Van Gerpen, 2004) and it is essential for ensuring a highquality biodiesel, avoiding the formation of solid deposits harmful for engine and emissions. Yet, norm D6751 is not enough to avoid the occurrence of some sediments that may occur from storage in variable weather conditions. This phenomenon is due to the presence of sterol glucosides and saturated MG not removed after transesterification, which can interact at longer time during storage and form solid sediments (Van Gerpen, 2004). Sterols can be 
1 found in vegetable oils (rapeseed, canola) but their presence is even higher in animal fats. The

2 presence of such contaminants may be detected by the cold soak filtration test (CSFT).

3 The final biodiesel composition results from three parallel-consecutive equilibrium reactions involving saturated and unsaturated long-chain alkyl molecules. The best method to obtain high quality biodiesel is fulfilling the biodiesel specifications at the reaction stage.

Using a large excess of methanol would allow in principle achieving very high conversions, in a single reactor, but in practice this approach is confronted with two drawbacks. Firstly, it increases the size of vessels and the energy consumption. These latter may be estimated from the vaporization energy $(1.2 \mathrm{MJ} / \mathrm{kg}$ methanol) and the cost of energy (15 $\$ / \mathrm{GJ})$ at $15 \$ / \mathrm{t}$ biodiesel for $100 \%$ methanol excess. Secondly, a large methanol excess does not guarantee the fulfillment of specifications. More methanol leads to the solubilization of glycerol in the FAME phase promoting the formation of mono-glycerides by the back reaction, such that more mono-glycerides are formed (Bambase et al., 2007). More suitable is the intermediate glycerol removal (Dimian and Bildea, 2008), which leads to a two-step reaction process, a method largely adopted in industry (Haas et al., 2006; Stiefel and Dassori, 2009; Air Liquid / Lurgi, 2017). An excess of methanol of 6:1 molar ratio is considered in general optimal. In the two-reactor sequence a split in the ratio of 70 to $30 \%$ was found optimal. Distillation under slight vacuum is necessary to recycle the excess of methanol. Note that low methanol content allows better separation of FAME and glycerol phases.

\subsubsection{Post-processing}

The resulting raw biodiesel and glycerol streams are sent to post-processing that is essentially a purification step aiming to remove the soaps and residual catalyst, as well as to correct the content of methanol and glycerol below the required limits, both in biodiesel and the glycerol by-product. Purification may be done by water washing, dry-wash and distillation.

The wet-wash scheme consists of removing the contaminants by extraction with water. The operation is energy-intensive implying neutralizations, waste water treatment, methanol distillation and glycerol drying. This scheme is adopted in conventional processes using alkali catalyst. Most of the soaps are captured in biodiesel, while most of the catalyst remains in glycerol. This method is effective for achieving the glycerol and methanol specs.

The dry-wash method applies ion-exchange resins or adsorbents for removing contaminants (Yawn, 2013). After several cycles the resin is regenerated, or the adsorbent dumped as solid waste. This approach is popular among small producers, as it avoids the drawback of wastewater treatment. Dry-wash makes use of adsorbents (Magnesol ${ }^{\circledR}$ and silica) or ion-exchange 
1 resin (Amberlite BD10 and Purolite PD 206). The resins can remove efficiently soap, glycerol and catalyst, but not methanol (Faccini et al., 2011). The action mechanism is based on ion exchange, filtration, adsorption and soap-glycerol interaction (Van Gerpen, 2010). The specific consumption is in the range of $800-1800 \mathrm{~L} / \mathrm{kg}$ resin, while the washing rate is 3 bed volumes per hour. The cost of resin and of regeneration may result finally in a cost of 2-5 \$/gallon or 5-13 \$/ton biodiesel (Kotrba, 2014).

Water-washing is more efficient than dry-wash, namely for higher content of contaminants (Van Gerpen, 2017b) and it is more appropriate when using alkali transesterification at larger scale. But in general, this method is penalized by the availability of water treatment facility. When solid catalysts are employed, the cost of purification is drastically reduced since the soap amount is low and there is no catalyst to remove. Hence dry wash is suitable and regards only glycerol reduction from the raw biodiesel.

High vacuum distillation of biodiesel has emerged recently as an advanced method to answer the higher quality requirements for biodiesel. However, the use of this costly technology must consider careful design constraints, as described in a later section.

\section{Results and discussion}

This section provides the main results for the FFA pre-treatment and the three integrated processes proposed, as well as their economic evaluation and comparison of performance.

\subsection{FFA pre-treatment}

The FFA pre-treatment can be carried out in a batch process (by esterification methanol or glycerol) or in a continuous process (by esterification methanol), as follows.

\subsubsection{Batch process}

FFA reduction by esterification with methanol. Figure 2 presents the flowsheet of esterification with methanol. Oil and methanol are put in contact in an autoclave with $5 \%$ wt sulfuric acid-to-FFA catalyst under vigorous stirring. This comprises of reaction vessel with heating jacket or heat exchanger, centrifugal separator (Tricanter, Flottweg company, 2008), methanol distillation tower, and oil dryer. The broken line means discontinuous operation, while the rest of the plant is operated continuously. A batch converts a feed of $2,500 \mathrm{~kg} / \mathrm{h}$ with $10 \%$ wt FFA. The refined oil ensures 4 hours of continuous operation, equivalent to $10,000 \mathrm{~kg}$ (or 11,000 L) oil inventory. Taking oleic acid as base molecule, the batch contains 9,000 kg (10.16 kmol) trioleine, 1,000 kg (3.54 kmol) oleic acid, and 3,398 kg (106.2 kmol) 
1 methanol in order to ensure a methanol to FFA molar ratio of 30:1. To this $50 \mathrm{~kg}$ sulfuric acid 2 is added; or $5 \%$ wt. The total mixture volume is $15.5 \mathrm{~m}^{3}$ hence considering a filling factor of 30.8 the required vessel volume is $20 \mathrm{~m}^{3}$. Flexibility in operation can be achieved by playing on temperature, acid concentration and methanol amount. Thus, for achieving a target of $0.5 \%$ FFA the reaction time can be estimated from the plots presented by Chai et al. (2014) at 90 $\min \left(\right.$ at $55^{\circ} \mathrm{C}$ ) and $60 \mathrm{~min}\left(\right.$ at $65{ }^{\circ} \mathrm{C}$ ), the maximum allocated time being 2 hours. Next, the batch content is treated with $\mathrm{Ca}(\mathrm{OH})_{2}$ solution for neutralization. Then oil, aqueous methanol and solid $\mathrm{CaSO}_{4}$ are separated by centrifugation and decanting filtering. Finally, the moisture is reduced to 500 ppm by vacuum drying, while methanol is distilled and recycled.

FFA reduction by esterification with glycerol. The esterification with glycerol is much simpler than with methanol. The reaction can run in a batch autoclave at $230-240{ }^{\circ} \mathrm{C}$ (heated with Dowtherm) using a molar ratio 1:1 for a reaction time of about 150 minutes. The reaction can be performed also in a PFR continuous device with variable residence time (Dimian and Rothenberg, 2016), as shown in a subsequent section. This method will be applied in the processes 2 and 3, as described later.

\subsubsection{Continuous process by FFA esterification with methanol}

Figure 3 presents a continuous process employing reactive absorption (RA) and heterogeneous catalysis. The key advantage is that catalyst neutralization and removal is no longer needed, which otherwise involved costly operations. The esterification of fatty acids with heterogeneous catalysts was investigated in studies regarding the design and simulation (Omota et al., 2003), catalyst synthesis (Kiss et al., 2006), alcohols (Grecea et al., 2012), and reactive separation processes (Kiss and Bildea, 2012). Kiss (2009) reported the application of RA by esterification of fatty acids with methanol when heterogeneous catalyst is employed. The simulation implemented here in Aspen Plus considers a feedstock of 2,525 kg/h with $2,250 \mathrm{~kg} / \mathrm{h}$ triolein and $250 \mathrm{~kg} / \mathrm{h}$ oleic acid as well as $25 \mathrm{~kg} / \mathrm{h}$ water. The oil stream enters the column at the top, in counter-current with $500 \mathrm{~kg} / \mathrm{h}$ methanol vapor produced in a stand-alone pressure vessel. Large excess methanol is necessary for reaction and to ensure proper liquid/vapor traffic over the internals. Kinetic data are available from the paper of Steinigeweg and Gmehling (2003), see equations (3) and (4) as well as Table 2. They studied this reaction in a laboratory column equipped with structured packing Katapak-SP in which ion-exchange resin catalyst Amberlyst-15 was inserted. 
1 Katapack-SP is compatible with Mellapak structured packing, both commercialized by Sulzer 2 ChemTech, for which hydraulic parameters are available in Aspen Plus. Physical data for 3 catalyst has been retrieved from the technical brochure regarding the superacid Amberlyst ${ }^{\mathrm{TM}}$ 15WET manufactured by DOW Chemical: particle size $0.6-0.85 \mathrm{~mm}$, bulk density $770 \mathrm{~g} / \mathrm{L}$, void fraction 0.4 , surface area $56 \mathrm{~m}^{2} / \mathrm{g}$ and maximum operating temperature $120^{\circ} \mathrm{C}$.

For the operations involving methanol/water mixture separation, the selected thermodynamic model was Wilson with parameters from the Aspen Plus database. Suitable results have been obtained with a column of 15 theoretical stages and catalyst holdup of $6 \mathrm{~kg}$ per stage, in total $90 \mathrm{~kg} / \mathrm{h}$ catalyst, using the heterogenous kinetic model (Table 2). Considering a column diameter of $0.42 \mathrm{~m}$ and HETP $0.6 \mathrm{~m}$ the hydraulic computation in Aspen Plus with Mellapack $750 \mathrm{Y}$ from Sulzer gives a volumetric holdup of $15 \mathrm{~L}$. Accordingly, the mass holdup of catalyst per stage is $0.77 \times(1-0.4) \times 15=6.9 \mathrm{~kg}$, which is $15 \%$ more than the actual value of 6 $\mathrm{kg}$ considered in simulation. The operation is at $\sim 80 \%$ of the maximum capacity. With a column pressure of $2.3 \mathrm{bar}$, top feed temperature at $95{ }^{\circ} \mathrm{C}$ and using methanol superheated at $108{ }^{\circ} \mathrm{C}$, the temperature profile is almost constant at $107{ }^{\circ} \mathrm{C}$, resulting in FFA conversion exceeding $99 \%$. Note that the homogeneous model results in a column design with the same sizing but operating at lower pressure of 1.5 bar. The temperature profile drops by $8^{\circ} \mathrm{C}$. Thus, the column's pressure is a key variable for controlling the process faced with disturbances in FFA content, as well as by catalyst deactivation.

The refined oil leaving the RD column with some methanol is suitable for transesterification. Water resulting from esterification with the excess methanol goes out as top vapor, being fed directly to the methanol distillation column operating at nearly atmospheric pressure. The column has 12 stages and is equipped with Pall rings (16 mm, ceramic). A molar reflux ratio of 1.0 ensures over $99.6 \%$ methanol recovery. Methanol is sent back to the RD column. The bottom stream is sent to wastewater treatment.

Table 2 presents sizing elements of the RD setup. Both columns have a diameter of $0.4 \mathrm{~m}$, except the stripping part of the methanol distillation tower (reduced to $0.3 \mathrm{~m}$ due to lower $\mathrm{V} / \mathrm{L}$ traffic). By comparing the two methods, the following differences may be noted:

- The amount of methanol is $3400 \mathrm{~kg}$ in batch treatment, but only 2,000 $\mathrm{kg}$ for $4 \mathrm{~h}$ operation in reactive absorption. The energy for methanol recycling is higher in the first case, but if one considers the ion-exchange regeneration the energy usage might be similar.

- The neutralization with $\mathrm{Ca}(\mathrm{OH})_{2}$ gives waste water to be treated and $\mathrm{CaSO}_{4}$ that should be landfilled. In contrast, the ion-exchange resin can be used on long-runs (months) without wastewater and with easy regeneration. The exhausted resin is also in much less amount. 
- The stainless-steel batch reactor is an expensive piece of equipment, to which the tricanter and dryer must be added.

- The reactive absorption is a standard piece of process equipment. In addition, the methanol distillation may be integrated with the transesterification process.

Consequently, the reactive absorption should be more advantageous than the batch treatment. (this will be checked later by the economic analysis). Table 6 presents the simulation results regarding the RA design flexibility with respect to FFA variability, considering feedstock with 10 and $15 \%$ wt FFA. In the first case the residual FFA is $0.42 \%$ (below the $0.5 \%$ norm), while in the second case the FFA is under $1 \%$ (still acceptable). The amount of methanol and the operating conditions can be controlled. As the reaction takes place in liquid phase, increasing the pressure can ensure a higher flexibility. If the pressure is raised to 3 bar it is possible to treat a $20 \%$ wt FFA feedstock to less than $0.2 \%$ wt. This result indicates that RA exhibits a large flexibility ensuring that a large variety of feedstock (UCO and animal fats) can be treated directly for FFA reduction.

\subsection{Integrated process design}

The integrated process combines the pre-treatment, transesterification and purification stages. The design of the reaction section is based on detailed kinetic modeling of reactors. The goal is to match the biodiesel quality specs after the reaction stage, thus avoiding the use energydemanding separations such as vacuum distillation. The content in TG, DG, and MG should be limited to $0.2,0.2$ and $0.8 \% \mathrm{wt}$, respectively, and to $0.25 \% \mathrm{wt}$ as total glycerine (see EN14214). The norms restrict the methanol, free glycerol and water content to under 0.2, 0.02 and $0.05 \% \mathrm{wt}$, respectively. Another important specification is the acid value, which is max $0.80 \mathrm{mg} \mathrm{KOH} / \mathrm{g}$ in D6751 norm and $0.50 \mathrm{mg} \mathrm{KOH} / \mathrm{g}$ in EN 14214. The last value is equivalent with $0.25 \%$ wt or $2500 \mathrm{ppm}$, taking the oleic acid as reference molecule. Thus, this specification sets the FFA conversion target in the FFA pre-treatment process.

Further, the impurities of alkali and earth alkali metals are limited to $5 \mathrm{ppm}$ each, while phosphorous to $10 \mathrm{ppm}$. The methanol specification in biodiesel and glycerol can be fulfilled by vacuum evaporation, although with different parameters. The recovered methanol is recycled back such to obtain a material balance closed to stoichiometry. For other specifications, the dry-wash purification method can be applied.

\subsubsection{Process 1: Homogenous catalysis process}

The application of reactive distillation (RD) as process intensification for transesterification 
1 was proposed by He and Thompson (2006). RD is usually applied by reactions controlled by chemical equilibrium when the product formation is enhanced by separation. In this case both product and reactant remain in the stream leaving the column at bottom. The intensification effect is not caused by separation but by creating a large excess of methanol, controlled by the energy injected in reboiler. In addition, the stages behave as a series of CSTRs. It was found that a RD scheme with pre-reactors (CSTR and PFR) is advantageous. The simulation of such process in a single stage showed that fulfilling the end-product specs is not possible, since the presence of large amounts of glycerol on the RD column stages combined with the countercurrent methanol flow tend to reform MG and DG by the reverse reactions. Hence the removal of glycerol before applying reactive distillation is mandatory.

The property model for transesterification is based on ideal assumption, due to large differences in the boiling points and no molecular interactions. For the liquid-liquid separation by decanting, the UNIFAC-Dortmund model was applied. Figure 4 shows the process flowsheet simulated with Aspen Plus v9.0, while Table 7 presents the key results in term of progress of transesterification. Firstly, the $2,500 \mathrm{~kg} / \mathrm{h}$ feedstock containing $10 \%$ FFA is treated in the RA column FFA-RD following the procedure described before. The conversion of FFA to methyl ester is over $99 \%$. Further, the resulting stream is submitted to transesterification. The reaction starts in a small CSTR $(500 \mathrm{~L}$ volume, 5 minutes residence time) operated at $70{ }^{\circ} \mathrm{C}$ and 3 bar and provided with intensive agitation to develop a stable dispersion. Methanol enters on inventory control to keep an inlet molar ratio methanol to oil at 6:1 when methanol recycle is added. TG conversion is $26.2 \%$, while DG and MG are formed in amounts of 67 and $32 \mathrm{~kg} / \mathrm{h}$ and help sustaining the liquid-liquid dispersion in the PFR-type device. Then the reaction continues in a tubular reactor. A multi-tubular serpentine device is suitable (Dimian and Rothenberg, 2016) provided with static mixers (Sulzer, 2018a). From a practical viewpoint, the reactor construction consists of 14 tubes of $0.25 \mathrm{~m}$ diameter and $2.5 \mathrm{~m}$ length, giving a total volume of $1.717 \mathrm{~m}^{3}$. The residence time is 20 minutes while the conversion rises to $84.5 \%$. The amounts of MG and DG are an order of magnitude higher than required by end-product specs, so even if the conversion is pushed to over $99 \%$ the specs cannot be met. Glycerol removal is required to push the equilibrium-controlled conversion. After cooling and neutralization, glycerol separation takes place by gravity decantation or centrifugation. The oil phase is submitted to a second transesterification. The ester stream enters the RD top stage. It contains $2,010 \mathrm{~kg} / \mathrm{h}$ ester and $413 \mathrm{~kg} / \mathrm{h} \mathrm{TG}, 36 \mathrm{~kg} / \mathrm{h} \mathrm{DG}$ and 63 $\mathrm{kg} / \mathrm{h}$ MG. This stream contains a fair amount of methanol $(286 \mathrm{~kg} / \mathrm{h})$, but this is insufficient for converting the remaining glycerides to the low limits fixed by specifications. A larger 
1 amount of methanol is recycled to the reaction space by the internal reflux, in turn controlled by the reboiler duty. A duty of $250 \mathrm{~kW}$ creates an internal methanol recycle of $\sim 300 \mathrm{~kg} / \mathrm{h}$. The addition of a small catalyst amount might by necessary. The RD column has 14 reactive stages provided with Sulzer structured packing (Sulzer, 2018b). A reactive volume of $10 \mathrm{~L}$ was assumed in simulation (checked later by hydraulic computation). The top pressure is at 1.8 bars, which results in a temperature of $87.2{ }^{\circ} \mathrm{C}$ that rises to $91{ }^{\circ} \mathrm{C}$ in the reactive zone. The ester leaves the column at $140{ }^{\circ} \mathrm{C}$ (at 2 bar pressure and some methanol content). The total packing height is $7.5 \mathrm{~m}$, giving a HETP of $0.535 \mathrm{~m}$. The total reaction volume is of $1.038 \mathrm{~m}^{3}$. Rigorous hydraulic calculation performed in Aspen Plus gives for Sulzer BX packing a holdup of $10 \mathrm{~L}$ (at $0.4 \mathrm{~m}$ diameter and above HETP), the operating point being at $60 \%$ from flooding. Sulzer CY packing (at 0.42 m diameter) gives a higher holdup of $14 \mathrm{~L}$ at $80 \%$ from the maximum capacity. Using the Sulzer CY packing ensures better flexibility in operation. Figure 5 shows the flow rates profile of the species on the RD column stages. A sharp drop on the top stages is noticed, but with an asymptotic trend to the bottom. The RD behaves as a series of small reactors. In this way, the bottom product reaches a composition that fulfils the specifications term of glycerides. Hydraulic computation confirms that the total residence time is 16 min. Thus, employing RD shows high efficiency although the reaction rate is very low due to approaching equilibrium, confirming the statement of He and Thompson (2006). After reaction completion, the bottom stream from RD joins the glycerol streams from D-1 forming the stream named FAME. This stream containing about $80 \%$ ester, $11 \%$ methanol and $7 \%$ Glycerol is sent to the top of the reboiled stripping column (DIST) for methanol recovery. This column receives also the vapor methanol stream from the FFA-RD column. The methanol distillation takes place under vacuum at 0.3 bar. Twelve theoretical stages ensure quantitative recovery of excess methanol, which is recycled. The methanol-free ester stream is sent to the separation of glycerol and biodiesel by decantation or centrifugation. The raw biodiesel is already in specs, except the glycerol amount which can be further reduced by dry-wash. The raw glycerol that has over $98 \%$ purity with methanol and salt as impurities is sent to purification. This may employ dry wash or wet wash (preferred) by state-of-the-art methods that were presented in a previous section. Table 8 presents a summary of the sizing of reactive distillation and methanol recovery columns. In terms of efficiency, the conversion of triglycerides in FAME, DG and MG is over 99.9\% while the FAME yield including FFA is $99.99 \%$. The raw biodiesel is already in the specs mentioned above. Namely the MG content, can be finely adjusted by means of the reboiler duty. Thus, considering the water- and catalyst-free biodiesel for $325 \mathrm{~kW}$ reboiler duty the 
1 FAME content is $98.9 \%$ wt while TG, DG and MG are $0.08,0.13$ and $0.72 \%$ wt, the rest 2 being methanol, glycerol and unreacted FFA.

3

\subsubsection{Process 2: Heterogeneous catalysis process}

Heterogeneous catalysis brings major advantages over homogeneous catalysis, by dropping operations involving water. A key benefit is obtaining high-purity glycerol as valuable byproduct. But the key problem is the availability of a robust and cost-competitive catalyst. The French company AXENS developed the Esterfip ${ }^{\mathrm{TM}}$ process based on a zinc aluminate catalyst used in a process for esters production from oils (Stern et al., 1999) or for the preparation of alcohol esters from triglycerides and alcohols (Bazer-Bachi et al., 2011). Despite intensive research, this catalyst remains the only one that proved active and robust in industrial operation. Details about technology can be found in patents (Bourney et al., 2005) and papers (Bloch et al., 2008) published by researchers from FPI. The preferred operating conditions are pressure of 40-70 bar, temperatures of $190-220{ }^{\circ} \mathrm{C}$, liquid hourly space velocity (LHSV) of 0.5-1 $\mathrm{h}^{-1}$, and $\mathrm{MeOH}$ :oil weight ratio 0.3:0.5. The catalyst consists of extrudates of $3 \mathrm{~mm}$ diameter. The reaction takes place in two steps, with intermediate conversion of $90-93 \%$.

A drawback of heterogeneous catalysis is that the reactor should be sufficiently oversized for dealing with the feedstock variability, the presence of impurities, and catalyst deactivation. To overcome these drawbacks, Dimian and Rothenberg (2016) proposed a novel design ensuring variable residence-time and easy catalyst replacement. The reaction device illustrated in the Figure 6 consists of a serpentine-type PFR assembled as vertical tubular segments filled with solid catalyst. A switching valve system is employed to connect or bypass the reaction tubes, and to easily replace the catalyst, all these without shutting down the reactor. As methanol and oil streams are pumped at high pressure, the mixing of reactants is realized by a static device exploiting the kinetic energy of flows. Heating and cooling tubular elements are provided for thermal conditioning before and after reaction. Energy savings are obtained by a FEHE builtin unit. Employing liquid thermal agent (Dowtherm) is convenient for small scale or mobile units. This reaction set-up allows adjusting the residence time to the feedstock type and to the catalyst activity by varying the number of the active tubes. Smaller catalyst grain can be used, resulting in a faster reaction rate by reducing the external and internal diffusion effects. In addition, a significant catalyst saving is obtained.

Figure 7 displays the flowsheet of a process including FFA pre-treatment by esterification with glycerol followed by transesterification using a solid catalyst. The plant is designed for a capacity of 2,500 kg/h feedstock containing variable FFA amounts $(20 \%$ wt FFA is used in 
1 this example). The simulation considers oleic acid and its glycerides as key components. The stream FFA-OIL is sent to FFA reduction by esterification with glycerol after preheating by the units FEHE-1 and H-1. The reaction takes place in the tubular reactor FFA-GLY provided with heating by Dowtherm. A reaction time of 150 minutes using a molar ratio GLY:FFA of 1:1 was found optimal by Tu at al. (2017), the FFA conversion being $90 \%$. In this project we aim $99 \%$ conversion and therefore the temperature is raised to $250{ }^{\circ} \mathrm{C}$. An amount of $500 \mathrm{~kg} / \mathrm{h}$ glycerol is used. The simulation of a PFR by kinetic modelling indicates that this conversion is achieved in 1.72 hours and reactor volume of $7.85 \mathrm{~m}^{3}$. Note that the conversion of FFA by esterification should be high enough to comply with the quality specifications, expressed as acid value. Considering oleic acid as reference molecule the FFA conversion should be at least 0.988 at $20 \%$ wt, and 0.992 at $35 \%$ wt oil content. This requirement is accomplished by the above described reactor design.

After pressure reduction at 1.1 bar, the cleaned oil is dried by flash evaporation. Using the hot effluent for feedstock preheating in the unit FEHE-1 results in energy savings of $70 \%$. Further, the oil and methanol are pumped at 40 bar (at 0.3 weight-ratio) and homogenized in a static mixer. The mixture is then heated up to $200{ }^{\circ} \mathrm{C}$ after passing through the FEHE-2 unit and the heater HX-2. Conditioned mixture enters the first reactor R-1 (an adiabatic PFR operating at constant temperature as the thermal effect is negligible). The design of R-1 aims to reach a conversion of TG close to $90-93 \%$. The hot outlet cooled in counter-current with the feed is sent to flash evaporator (FL-1) after pressure reduction to 2 bar. Lower methanol amount makes phase separation easier. After cooling at $35{ }^{\circ} \mathrm{C}$ the liquid mixture is sent to the glycerol removal in the decanter (D-1).

The process continues in the second transesterification reactor R-2, by remixing ester and recovered methanol, and rising the pressure and temperature to the previous values. After the reactor R-2, the conversion should be over $99.7 \%$ to meet the biodiesel specifications. After heat recovery by the unit FEHE-3 the reactor outlet stream is sent to the stripping column DIST, provided with 4 theoretical stages and operates under vacuum at 0.3 bar. The top distillate delivers methanol to be recycled to the transesterification reactors. Methanol recovery of $99.5 \%$ is necessary for enhancing the glycerol separation and for reducing the methanol content in product below $0.2 \%$ wt. The final separation takes place in unit D-2, which delivers raw biodiesel that complies with the specs, except glycerol set by phase equilibrium. Gravity driven separators D-1 and D-2 can be replaced by centrifuges.

Table 9 presents the main elements regarding the reactor sizing (note that each reactor employs two serpentine-type modules). Figure 8 shows the concentration profiles of key 
1 species. The methanol flowrate reduces from 294.2 to $286.2 \mathrm{~kg} / \mathrm{hr}$ in R-2 (but not shown in

2 Figure 8-right, as it is out of the scale). The plot is typical for consecutive / parallel reactions,

3 in which DG and MG are intermediates. Although the TG conversion in the first reactor reaches $93 \%$, the concentrations of DG and MG are higher than end-product specs by an order of magnitude. Hence the need for using a second reactor is obvious. The residence (spatial) times are similar in both reactors, about 1 hour. The flow superficial velocity (a key parameter for ensuring good mass transfer) is about $3 \mathrm{~mm} / \mathrm{s}$, in agreement with best practice of liquidphase reactors. The results prove that kinetic modeling offers a realistic description of the transesterification reaction in industrial conditions (Bloch et al., 2008). The efficiency of this process is excellent as can be expressed as follows:

- TG conversion $99.98 \%$, full quantitative FAME yield with reference to oil and FFA

- Raw biodiesel: FAME content 99.41, MR 0.017, DG 0.013, MG 0.28, GL 0.032, FFA 0.18 all in \%wt.

\subsubsection{Process 3: Heterogeneous catalysis and vacuum distillation} In this alternative, the 2 nd reaction stage is suppressed and replaced by a vacuum distillation of the FAME stream obtained from R-1. The goal here is realizing an advanced purification of the top product to match the requirements of EN 14241 and D6751 standards. As drawback of biodiesel distillation, a loss in material of 3-10 \% was noted (Van Gerpen, 2012), which clearly affects the profitability. The reboiler temperature must be limited to avoid thermal biodiesel degradation. Below $270{ }^{\circ} \mathrm{C}$ the degradation should be negligible (Lin et al., 2013). The limit may be raised to $300{ }^{\circ} \mathrm{C}$ but not exceeding 20 minutes. The vacuum should be fitted to this requirement.

Figure 9 presents the process flowsheet, in which the esterification with glycerol is handled as described in the previous process while the transesterification is carried out in a single PFR by using heterogeneous catalysis at $210{ }^{\circ} \mathrm{C}$ and 40 bar. In a first attempt the oil has $20 \%$ wt FFA, which is further raised to $35 \%$ wt to explore the process flexibility. The thermodynamic model is ideal, except the liquid-liquid separation where the UNIFAC-Dortmund method was applied. The methanol-to-oil weight-ratio is $0.3(750 / 2,500 \mathrm{~kg} / \mathrm{h})$. The conversion of TG in the reactor is pushed to over $98 \%$ in order to minimize the recycle to the reactor, but also to ensure feasible temperatures by vacuum distillation. The profile of species flowrates in the catalytic reactor is similar to Figure 8, left. A large amount of MG is still present in the stream after reaction, about 7 to $8 \%$ with respect to FAME ester, formed by FFA esterification in the pre-treatment step, as well as the unconverted FFA from the pre-treatment stage. The 
1 methanol is recovered for the most part in the flash FL-1, followed by the separation of raw 2 glycerol in the decanter D-1, from which high purity glycerol is obtained by the evaporation. 3 The FAME stream is then submitted to distillation after preheating. The methanol flows from 4 flash separation, glycerol purification and FAME distillation are gathered in a recycle stream. The vacuum distillation aims to reduce the amount of glycerides in biodiesel (top distillate), namely MG, far below the specifications of above mentioned norms. This is possible because of large volatility differences between the methyl esters and the corresponding glycerides. The reboiler temperature should be kept below $300{ }^{\circ} \mathrm{C}$, better under $270{ }^{\circ} \mathrm{C}$. Vacuum distillation is a suitable purification method, if some precautions are taken. The column's pressure should be selected such to operation costs by considering the temperature constraints. In this case a pressure of 0.1 bar is suitable.

The separation of FAME versus glycerides needs only 6 theoretical stages. The bottom temperature may be limited by allowing a suitable amount of FAME to be recycled. The top temperature may be controlled by means of the condenser duty that determines also the vapor distillate flow and composition. In this way it is possible to recover $99.9 \%$ of the methanol with only very limited amount of FAME losses (under $0.05 \%$ ). The mass reflux of $1,500 \mathrm{~kg} / \mathrm{h}$ or molar reflux ratio of 0.77 ensure a wide operation range of internals. The simulation shows that the column operates correctly ( 80 to $90 \%$ from flooding) if structured packing is used, as Sulzer BX or BX Plus, but not random packing or sieve trays. The column sizing leads to a $1.0 \mathrm{~m}$ diameter and total packing height $3.0 \mathrm{~m}$, while the pressure drop is only $0.076 \mathrm{bar}$. The reboiler temperature is kept below $280{ }^{\circ} \mathrm{C}$. The heating can be done with organic thermal fluid, as Dowtherm Q that works well up to $330{ }^{\circ} \mathrm{C}$ at 3.4 bar (Dimian et al., 2014). This may be used in close cycle for heating other high temperature units, namely the chemical reactors. The use of high temperature raises the problem of energy usage which can be reduced significantly by heat integration. FEHE units are used to take advantage of the hot reactor outlet, as shown in Figure 7 and Figure 9. Hot biodiesel distillate can be used to drive the glycerol evaporator. Further options can be explored by applying Pinch technology, but this is outside the goal of this research.

The efficiency of this process is excellent delivering a quantitative FAME yield. The quality of the final product surpasses the required specifications: over 99.6 \%wt FAME and only few ppm of glycerides. The residual acid content is 1400 ppm by $20 \%$ wt initial FFA and 1950 ppm by $35 \%$ wt, by keeping the same operation parameters. The methanol is below $0.20 \% \mathrm{wt}$, and only the glycerol amount needs a slight correction by dry-wash. 


\subsection{Economic evaluation}

Before detailing the economic analysis, note that the three processes were optimized with respect to units' sizing and the energy use but aiming to offer also an operational flexibility. The key optimization parameters, as temperatures, methanol/oil ratio and catalyst amount were selected in the optimal range. The reactors were sized to cope with the specifications, while the flexibility may be obtained by the adjustment of temperature. The distillation columns have been oversized by about $30 \%$ as number of stages. The heat integration opportunities have been identified by running the Energy Analyzer tool in Aspen Plus. Thus, in the Process 1 that works at lower temperature, the heat integration possibilities are limited, as it may be seen from the duties of units presented in Figure 1. On the contrary, the heat integration is compulsory in Process 2 and 3, where it was implemented by means of FEHE units. Table 5, Table 8, and Table 9 present the sizing elements of the key units.

Table 10 summarizes the economic evaluation of all processes, which lists the capital costs in terms of Purchased Cost of Equipment (PCE) and Installed Cost (IC) of the key equipment items, as calculated using Aspen Process Economic Analyzer. The values correspond to individual flowsheet items, lumped as reactors, separators, heat exchangers and pumps. Process 1 (employing RD) has the lowest cost, about $20 \%$ of the other two processes which have similar costs. The cost of reactors is higher, but the separators and heat exchangers cost much less, while the cost of pumps is negligible. Process 2 and 3 use similar techniques in pre-treatment and reaction, but Process 3 uses a demanding separation (high temperature vacuum distillation) whose cost is compensated by the simplification of the reaction section.

A complete evaluation should consider the cost of purification that leads to similar quality of the products. Process 1 needs more capital and energy cost for purification due to the need to remove soaps and catalyst from both biodiesel and glycerol. Water washing is recommended, but it involves higher equipment and energy costs. The purification of Process 2 and 3 is much cheaper. The overall result is that all three processes have similar investment costs. The selection depends on the availability of catalyst, Process 1 being the most convenient. When heterogeneous catalyst is selected, Process 3 is recommended as it delivers a better quality of biodiesel, and it is also more capable to treat feedstock of high FFA content.

Table 11 presents the key performance indicators in terms of utility requirements and costs, heating duties, specific energy usage, and $\mathrm{CO}_{2}$ emissions. Despite very different flowsheets and operation conditions, the processes have similar performance. As Process 1 works at low to moderate temperatures and pressures, the energy usage is low. The situation changes if wet washing (which is energy-intensive) is selected for purification. Process 2 and 3 (employing 
1 heterogeneous catalysis) work at higher temperature but show moderate energy usage due to energy integration. The utility cost in Process 2 is somewhat higher because of the electricity involved in high pressure pumping. Despite using energy intensive vacuum distillation, Process 3 has low energy use and moderate utility cost.

\section{Conclusions}

This study showed that converting waste lipids to biodiesel by integrated eco-efficient processes is profitable for biofuel manufacturers while being environmentally friendly. Many researchers explored this topic from the viewpoint of chemistry and technology, but this study is the first to provide an integrated analysis of process design issues, including the recent progress in reaction and separation methods. The results are based on rigorous simulations employing detailed kinetic modeling of reactors for both esterification and transesterification, in view of fulfilling the biodiesel specifications, namely the bound glycerol and the acid value. Using reactive separations and heterogeneous catalysis leads to significant savings in resources, energy and equipment. The main conclusions drawn are summarized as follows:

- The esterification with methanol by reactive absorption using solid catalysts (superacid ion-exchange resins) is suitable for feedstock pre-treatment of low and moderate FFA content $(<15 \% \mathrm{wt})$ such as UCO. This method is cost-effective as equipment and energy, and more beneficial than batch treatment, by avoiding neutralization, distillation and drying.

- The esterification with glycerol can be performed even without catalyst (working at $250{ }^{\circ} \mathrm{C}$ and over 1.5 hours reaction time), being suitable for pre-treating high FFA feedstock $(>15 \% \mathrm{wt})$. The higher temperature is compatible with the transesterification using heterogeneous base catalyst.

- Process 1 (suitable for a feedstock below $15 \%$ wt FFA) handles the FFA pre-treatment by reactive absorption and the transesterification by homogeneous alkali catalysis. RA reduces the FFA content below $0.5 \%$ wt. The reaction setup for transesterification is built-up from a CSTR and PFR leading to a conversion of up to 92\%. After glycerol removal, a reactive distillation unit is used to reach biodiesel quality specifications. This process shows the lowest investment cost regarding the pre-treatment and processing stages.

- Process 2 may reduce the high FFA feedstock up to $35 \%$ wt by autocatalytic esterification with glycerol at $250{ }^{\circ} \mathrm{C}$ in a plug-flow reactor and conversion around 
99\%. The resulting mono- and di-glycerides enter directly the transesterification stage that employs solid catalyst operating at high pressure (35-40 bar) and temperature (190-220 $\left.{ }^{\circ} \mathrm{C}\right)$. A two-stage reaction with intermediate glycerol separation is used. A new reactor design is applied (multi-tubular reactor with variable residence time and easy catalyst change). Despite high temperatures in reactors low energy use is achieved by heat integration.

- Process 3 is similar to the second one, but the 2 nd transesterification stage is replaced by vacuum distillation. The first reaction stage runs at $98 \%$ TG conversion, but the amount of mono-glycerides is substantial, due to the pre-treatment stage. Vacuum distillation (operated at 0.1 bar) plays a key role by recycling the monoglycerides to transesterification. The design is constrained by keeping the reboiler temperature below $280{ }^{\circ} \mathrm{C}$ to avoid thermal degradation. This condition is realized by ensuring a suitable amount of FAME in the bottom stream recycled to reactor. Low energy consumption is achieved by heat integration.

- Economic analysis shows an advantage of Process 1 in terms of capital investment and utility consumption for the pre-treatment and processing stage, but the overall benefit is less when considering the purification, as the alkali catalysis implies higher costs of materials / energy than processes using solid catalysts (Process $2 \& 3$ ). Also, high purity glycerol is obtained by heterogeneous catalysis, which brings a substantial credit for the biodiesel price. Among them, Process 3 leads to highest quality biodiesel that largely fulfils the EN14214 and CSFT standards.

- The selection of technology depends on the available catalyst and the FFA amount in feedstock. Process 1 is more suitable for low FFA feedstock, while Process 2 and 3 are convenient for high FFA feedstock while moving away from the constraints and drawbacks of using homogeneous catalyst, but with a more demanding technology.

The proposed integrated biodiesel production processes allow the eco-efficient conversion of cheap waste lipids into valuable biofuels, by using advanced technologies and catalysts.

\section{Acknowledgement}

Financial support of the European Commission through the European Regional Development Fund and of the Romanian state budget, under the grant agreement 155/25.11.2016 (Project POC P-37-449, acronym ASPiRE) is gratefully acknowledged. AAK gratefully acknowledges the Royal Society Wolfson Research Merit Award. 


\section{References}

1. Allain, F., Portha, J. F., Girot, E., Falk, L., Dandeu, A., Coupard, V., 2016. Estimation of kinetic parameters and diffusion coefficients for the transesterification of triolein with methanol on a solid $\mathrm{ZnAl}_{2} \mathrm{O}_{4}$ catalyst. Chem. Eng. J., 283, 833-845. https://doi.org/10.1016/j.cej.2015.07.075

2. Air Liquide / Lurgi, 2017. Biodiesel ultra low in precipitates. Technical brochure.

3. Atadashi, I. M., Aroua, M. K., Abdul, Aziz A. R., Sulaiman, N. M. N., 2012. Production of biodiesel using high free fatty acid feedstocks, Renew. Sustain. Energy Rev., 16(5), 3275-3285. https://doi.org/10.1016/j.rser.2012.02.063

4. Bambase, M. E., Jr., Nakamura Naka, J., Matsumara M., 2007. Kinetics of hydroxidecatalysed methanolysis of crude sunflower oil for the production of fuel-grade methyl esters, J. Chem. Technol. Biot., 82, 273-280. https://doi.org/10.1002/jctb.1666

5. Bazer-Bachi, D., Coupard, V., Maury, S., Pugnet, V., Clemencon, I., Quoineaud, A. A., 2011. Heterogeneous catalyst of the zinc aluminate and use thereof in a process for preparation of alcohol esters from triglycerides and alcohols. US patent no. US20110092730A1.

6. Bournay, L., Hillion, G., Boucot, P., Chodorge, J., Bronner, C., Forestiere, A., 2005. Process for producing alkyl esters from a vegetable or animal oil and an aliphatic monoalcohol. US Patent no. US6878837B2.

7. Bloch, M., Bournay, L., Casanave, D., Chodorge, J. A., Coupard, V., Hillion, G., Lorne, D., 2008. Fatty acid esters in Europe: Market trends and technological perspectives, Oil \& Gas Sci. Technol. - Rev. IFP, 63, 405-418. https://doi.org/10.2516/ogst:2008034

8. Chai, M., Tu, Q., Lu, M., Yang, Y. J., 2014. Esterification pretreatment of free fatty acid in biodiesel production, from laboratory to industry, Fuel Proc. Technol. 125, 106-113. https://doi.org/10.1016/j.fuproc.2014.03.025

9. Chakraborty, R., Gupta, A. K., Chowdhury, R., 2014. Conversion of slaughterhouse and poultry farm animal fats and wastes to biodiesel: Parametric sensitivity and fuel quality assessment, Renew. Sustain. Energy Rev., 29, 120-134. https://doi.org/10.1016/j.rser.2013.08.082

10. Chang, A-F., Liu, Y. A., 2010. Integrated process modelling and product design of biodiesel manufacturing. Ind. Eng. Chem. Res., 49 1197-1213. https://doi.org/10.1021/ie9010047

11. Chuah, L. F., Klemeš, J. J., Yusup, S., Bokhari, A., Akbard, M. M., 2017. A review of cleaner intensification technologies in biodiesel production, J. Clean. Prod., 146(10), 181193. https://doi.org/10.1016/j.jclepro.2016.05.017

12. Dimian A. C., Bildea C. S., 2008. Chemical process design case studies. Wiley-VCH, 
Weinheim, Germany.

13. Dimian, A. C., Rothenberg, G., 2016. An effective modular process for biodiesel manufacturing using heterogeneous catalysis. Catal. Sci. Technol., 6, 6097-6108. https://doi.org/10.1039/C6CY00426A

14. Dimian, A. C., Srokol, Z., Mittelmeijer-Hazeleger, M. C., Rothenberg, G., 2010. Interrelation of chemistry and process design in biodiesel manufacturing by heterogeneous catalysis, Top Catal., 53, 1197-1201. https://doi.org/10.1007/s11244-010-9562-0

15. Enweremadu, C. C., Mbarawa, M. M., 2009. Technical aspects of production and analysis of biodiesel from used cooking oil - A review, Renew. Sustain. Energy Rev., 13(9), 22052224. https://doi.org/10.1016/j.rser.2009.06.007

16. Faccini, C. S., Caramão, E. B., 2011. Dry washing in biodiesel purification: Comparative study of adsorbents, J. Braz. Chem. Soc., 22(3), 558-563. https://doi.org/10.1590/S010350532011000300021

17. Felizardo, P., Machado, J., Vergueiro, D., Correia, M. J. N, Gomes, J. P., 2011. Study on the glycerolysis reaction of high free fatty acid oils for use as biodiesel feedstock, Fuel Proc. Technol., 92, 1225-1229. https://doi.org/10.1016/j.fuproc.2011.01.020

18. Flottweg Company, 2018. Innovative bowl decanter technology, www.flottweg.com 19. Grecea, M. L., Dimian, A. C., Tanase, S., Subbiah, V., Rothenberg, G., 2012. Sulfated zirconia as a robust superacid catalyst for multiproduct fatty acid esterification, Catal. Sci. Technol., 2, 1500-1506. https://doi.org/10.1039/C2CY00432A

20. Gmehling, J., Wittig, R., Lohmann, J., Joh, R., 2002. A Modified UNIFAC (Dortmund) Model. 4. Revision and extension, Industrial \& Engineering Chemistry Research, 41, 1678-1688. https://doi.org/10.1021/ie0108043

21. Haas, M. J., McAloon, A. J., Yee, W. C., Foglia, T. A., 2006. A process model to estimate biodiesel production costs. Bioresour. Technol. 97, 671-678. https://doi.org/10.1016/j.biortech.2005.03.039

22. Hajjari, M., Tabatabaei, M., Aghbashlo, M., Ghanavati, H., 2017. A review on the prospects of sustainable biodiesel production: A global scenario with an emphasis on waste-oil biodiesel utilization, Renew. Sustain. Energy Rev., 72, 445-464. https://doi.org/10.1016/j.rser.2017.01.034

23. He, B. B., Singh, A. P., Thompson, J. C., 2006. A novel continuous-flow reactor using reactive distillation for biodiesel production, Transactions of the ASABE, 49(1), 107-112. https://doi.org/10.13031/2013.20218

24. Kiss, A. A., 2009. Novel process for biodiesel by reactive absorption, Separation and Purification Technology, 69, 280-287. https://doi.org/10.1016/j.seppur.2009.08.004 25. Kiss, A. A., 2014. Process intensification technologies for biodiesel production, Springer, 
Heidelberg, Germany. https://doi.org/10.1007/978-3-319-03554-3

26. Kiss, A. A., Bildea, C. S., 2012. A review on biodiesel production by integrated reactive separation technologies, J. Chem. Technol. Biot., 87, 861-879. https://doi.org/10.1002/jctb.3785

27. Kiss, A. A., Dimian, A. C., Rothenberg, G., 2006. Solid acid catalysts for biodiesel production - Towards sustainable energy, Adv. Synth. Catal., 348, 75-81. https://doi.org/10.1002/adsc.200505160

28. Kiss, A. A., Lange, J. P., Schuur, B., Brilman, D. W. F., van der Ham, A. G. J., Kersten, S. R. A., 2016. Separation technology - Making a difference in biorefineries, Biomass Bioenergy, 95, 296-309. https://doi.org/10.1016/j.biombioe.2016.05.021

29. Knothe, G., 2008. Designer biodiesel: Optimizing fatty ester composition to improve fuel properties, Energy Fuels, 22, 1358-1364. https://doi.org/10.1021/ef700639e

30. Knothe, G., 2009. Improving biodiesel fuel properties by modifying fatty ester composition, Energy Environ. Sci., 2(7), 759-766. https://doi.org/10.1039/B903941D

31. Knothe, G., Krahl, J., van Gerpen, J., 2010. The biodiesel handbook, Academic Press and AOCS Press, Urbana, Illinois, USA.

32. Knothe, G., Steidley, K. R, 2009. A comparison of used cooking oils: A very heterogeneous feedstock for biodiesel. Bioresour. Technol., 100, 5796-5801. https://doi.org/10.1016/j.biortech.2008.11.064

33. Kotrba, R., 2014. Biodiesel separation, washing and polishing: Upstream and downstream considerations, Biodiesel Magazine, March 03 issue.

34. Lin, R., Zhu, Y., Tavlarides, L. L., 2013. Mechanism and kinetics of thermal decomposition of biodiesel fuel. Fuel 106, 593-604. https://doi.org/10.1016/j.fuel.2012.12.013

35. Likozar, B., Levec, J., 2014. Effect of process conditions on equilibrium, reaction kinetics and mass transfer for triglycerides transesterification to biodiesel: experimental and modelling based on fatty acid composition. Fuel Proc. Technol., 122, 30-41. https://doi.org/10.1016/j.fuproc.2014.01.017

36. Macombe, C., Leskinen, P., Feschet, P., Antikainen, R., 2013. Social life cycle assessment of biodiesel production at three levels: a literature review and development needs, J. Clean. Prod., 52, 205-216. https://doi.org/10.1016/j.jclepro.2013.03.026

37. Maddikeri, G. L., Pandit, A. B., Gogate, P.R., 2012. Intensification approaches for biodiesel synthesis from waste cooking oil: A review, Ind. Eng. Chem. Res., 51(45), 14610-14628. https://doi.org/10.1021/ie301675j

38. Math, M. C., Kumar, S. P., Chetty, S. V., 2010. Technologies for biodiesel production from used cooking oil - A review, Energy Sustain. Dev., 14(4), 339-345. 
https://doi.org/10.1016/j.esd.2010.08.001

39. Moser, B. R., 2009. Biodiesel production, properties, and feedstocks, In Vitro Cell. Dev. Biol. - Plant, 45, 229-266. https://doi.org/10.1007/s11627-009-9204-Z

40. Noureddini, H., Zhu, D., 1997. Kinetics of transesterification of soybean oil, Journal of the American Oil Chemists' Society, 74 (11), 1457-1463. https://doi.org/10.1007/s11746997-0254-2

41. Omota, F., Dimian, A. C., Bliek, A., 2003. Fatty acid esterification by reactive distillation. Part1: Equilibrium-based design, Chem. Eng. Sci., 58, 3159-3174. https://doi.org/10.1016/S0009-2509(03)00165-9

42. Rohman, A., Triyana, K., Sismindari, S., Erwanto, Y., 2012. Differentiation of lard and other animal fats based on triacylglycerols composition and principal component analysis, Int. Food Res. J., 19(2): 475-479.

43. Steinigeweg, S., Gmehling, J., 2003. Esterification of a fatty acid by reactive distillation, Ind. Eng. Chem. Res., 42, 3612-3619. https://doi.org/10.1021/ie020925i

44. Stiefel, S., Dassori, G. 2009. Simulation of biodiesel production through transesterification of vegetable oils. Ind. Eng. Chem. Res., 48, 1068-1071. https://doi.org/10.1021/ie8005512

45. Venkatesh, S., van Zwol, P., Dimian, A. C., Gitis, V., Rothenberg, G., 2014. Glycerol esters from real cooking oil using a robust acid catalyst. Top. Catal., 57, 1545-1549. https://doi.org/10.1007/s11244-014-0337-x

46. Vicente, G., Martinez Aracil, M. J., Esteban, A., 2005. Kinetics of sunflower oil methanolysis, Ind. Eng. Chem. Res., 44, 5447-5454. https://doi.org/10.1021/ie040208j

47. Stern, R., Hillion, G., Rouxel, J. J., Leporq, S., 1999. Process for the production of esters from vegetable oils or animal oils alcohols. United State Patent No. 5908946.

48. Sulzer Chemtech, 2018a. Mixing and reaction technology. www.sulzer.com

49. Sulzer Chemtech, 2018b. Structured packing for separation and reactive distillation, www.sulzer.com

50. Tu, Q., Lu, M., Knothe, G., 2017. Glycerolysis with crude glycerin as an alternative pretreatment for biodiesel production from grease trap waste: Parametric study and energy analysis, J. Clean. Prod., 162, 504-511. https://doi.org/10.1016/j.jclepro.2017.06.064

51. UFOP (German Research for Oil and Protein Plants), 2017. Report on Global Market Supply 2017/2018. European and world demand for biomass for biofuel production in relation to supply in the food and feedstuff markets. Available at www.ufop.de, Last accessed 15 Feb. 2018.

52. Van Gerpen, J., Shanks, B., Pruszko, R., Clements, D., Knothe, G., 2004. Biodiesel production technology, NREL report NREL/SR-510-36244, National Renewable Energy 
Laboratory, Colorado, USA.

53. Van Gerpen, J. H., 2010. Ion exchange resin for cleaning biodiesel: How do they work? Technote 10, University of Idaho, Indiana, USA.

54. Van Gerpen, J. H., 2017a. Cold soak filtration test. Technote 19, University of Idaho, Indiana, USA

55. Van Gerpen, J. H., 2017b. The advantages of water washing biodiesel. Technote 25, University of Idaho, Indiana, USA.

56. Wang, Y., Ma, S., Wang, L., Tang, S., Riley, W. W., Reaney, M. J., 2012. Solid superacid catalyzed glycerol esterification of free fatty acids in waste cooking oil for biodiesel production, European Journal of Lipid Science and Technology, 114, 315-324. https://doi.org/10.1002/ejlt.201100111

57. Yawn, R., 2013. Ion exchange resin as dry wash media. Biodiesel Magazine. March 12 issue.

58. Zhang, Y., Dubé, M. A., McLean, D. D., Kates, M., 2003a. Biodiesel production from waste cooking oil: 1. Process design and technological assessment, Bioresour. Technol., 89, 1-16. https://doi.org/10.1016/S0960-8524(03)00040-3

59. Zhang, Y., Dubé, M. A., McLean, D. D., Kates, M., 2003b. Biodiesel production from waste cooking oil: 2. Economic assessment and sensitivity analysis. Bioresour. Technol., 90, 229-240. https://doi.org/10.1016/S0960-8524(03)00150-0

60. Zong, L., Ramanathan, S., Chen, C. C., 2010. Fragment-based approach for estimating thermophysical properties of fats and vegetable oils for modeling biodiesel production processes. Ind. Eng. Chem. Res., 49, 876-886. https://doi.org/10.1021/ie900513k 


\section{$1 \quad$ Tables}

3 Table 1. Fatty acid profile of some vegetable oil and waste lipids*

\begin{tabular}{|c|c|c|c|c|c|c|c|c|}
\hline Fatty acid & Palmitic & Stearic & Oleic & Linoleic & Linolenic & Ratio US & CN & PP \\
\hline Formula & $16: 0$ & $\mathrm{C} 18: 0$ & $\mathrm{C} 18: 1$ & $\mathrm{C} 18: 2$ & $\mathrm{C} 18: 3$ & - & - & ${ }^{\circ} \mathrm{C}$ \\
\hline Palm & $40-47$ & $3-6$ & $52-65$ & $6-12$ & - & 1.1 & 55 & 6 to 10 \\
\hline Rapeseed & 4 & 2 & $58-60$ & $9-23$ & $1-13$ & 15.7 & $48-55$ & -9 to 3 \\
\hline Sunflower & $3-8$ & $1-6$ & $14-43$ & $44-74$ & - & 10.1 & $54-58$ & -3 to 3 \\
\hline Soybean & 11 & 4 & $21-24$ & $49-53$ & $7-8$ & 5.7 & $48-52$ & 0 \\
\hline UCO & $5-20$ & $5-30$ & $50-70$ & $10-20$ & - & 1.9 & $54-60$ & $-3-3$ \\
\hline Tallow & $27-44$ & $25-37$ & $9-34$ & $14-50$ & $26-50$ & 1.0 & $60-62$ & $9-13$ \\
\hline Poultry fat & 23 & 6 & 43 & 20 & 8 & 2.4 & - & - \\
\hline Lard & 21 & 18 & 39 & 21 & 1 & 1.6 & - & - \\
\hline
\end{tabular}

*Note: Data collected from various sources (Knothe et al., 2008, 2010; Rohmans et al., 2012)

Table 2. Kinetic parameters for FFA esterification with methanol using Amberlyst-15 catalyst (Steingeweg and Gmehling, 2003)

\begin{tabular}{|l|c|c|c|c|}
\hline Parameters & $\mathbf{K}_{\mathbf{i}}$ & $\mathbf{E}_{\mathbf{a i}}$ & $\mathbf{k}_{\mathbf{i}}$ & $\mathbf{E}_{\mathbf{a i}}$ \\
\hline Units & $\mathrm{kg} / \mathrm{kmol} / \mathrm{s}$ & $\mathrm{kJ} / \mathrm{mol}$ & $\mathrm{kg} / \mathrm{kmol} / \mathrm{s}$ & $\mathrm{kJ} / \mathrm{mol}$ \\
\hline Esterification, $\mathrm{i}=1$ & $9.116 \times 10^{5}$ & 68.71 & $3.18 \times 10^{6}$ & 72.23 \\
\hline Hydrolysis, $\mathrm{i}=-1$ & $1.498 \times 10^{4}$ & 64.66 & $3.55 \times 10^{5}$ & 71.9 \\
\hline Sorption constant $\mathrm{K}_{\mathrm{S}}$ & None & - & 2.77 & - \\
\hline
\end{tabular}

9

10

Table 3. Kinetic parameters by transesterification with alkali catalyst (Bambase et al., 2007)

\begin{tabular}{|c|c|c|c|c|c|c|c|}
\hline & & $k_{1}$ & $k_{-1}$ & $k_{2}$ & $k_{-2}$ & $k_{3}$ & $k_{-3}$ \\
\hline$k_{0, i}$ & $\mathrm{~L} / \mathrm{mol} / \mathrm{s}$ & $2.40 \times 10^{6}$ & $1.68 \times 10^{3}$ & $1.91 \times 10^{8}$ & $2.92 \times 10^{6}$ & $4.07 \times 10^{2}$ & $1.04 \times 10^{6}$ \\
\hline$\overline{E_{a, i}}$ & $\mathrm{~J} / \mathrm{mol}$ & 58,771 & 44,953 & 67,181 & 58,215 & 30,026 & 46,033 \\
\hline$k\left(50^{\circ} \mathrm{C}\right)$ & $\mathrm{L} / \mathrm{mol} / \mathrm{min}$ & 0.0451 & 0.0054 & 0.1565 & 0.0674 & 0.3404 & 0.0224 \\
\hline$K_{e q}\left(50^{\circ} \mathrm{C}\right)$ & & \multicolumn{2}{|c|}{8.346} & \multicolumn{2}{|c|}{2.323} & \multicolumn{2}{|c|}{15.218} \\
\hline$k\left(60^{\circ} \mathrm{C}\right)$ & $\mathrm{L} / \mathrm{mol} / \mathrm{min}$ & 0.087 & 0.009 & 0.332 & 0.129 & 0.476 & 0.037 \\
\hline$K_{e q}\left(60^{\circ} \mathrm{C}\right)$ & & \multicolumn{2}{|c|}{9.741} & \multicolumn{2}{|c|}{2.568} & \multicolumn{2}{|c|}{12.724} \\
\hline
\end{tabular}


2 Table 4. Kinetic parameters by transesterification with heterogeneous catalyst (adapted from Allain et al., 2016)

\begin{tabular}{|l|l|l|l|l|}
\hline & Reaction & $k_{0} /\left[\mathrm{m}^{6} \mathrm{~kg}-\mathrm{cat} / \mathrm{kmol} / \mathrm{s}\right]$ & $E_{a} /[\mathrm{kJ} / \mathrm{mol}]$ & $K_{e q}$ \\
\hline 1 & TG+MeOH $\rightleftharpoons \mathrm{DG}+\mathrm{FAME}$ & 3.15 & 64.6 & 51.2 \\
\hline 2 & $\mathrm{DG}+\mathrm{MeOH} \rightleftharpoons \mathrm{MG}+\mathrm{FAME}$ & $2.22 \times 10^{-3}$ & 31.8 & 53.1 \\
\hline 3 & $\mathrm{MG}+\mathrm{MeOH} \rightleftharpoons \mathrm{GLY}+\mathrm{FAME}$ & $3.18 \times 10^{-5}$ & 17.0 & 12.2 \\
\hline
\end{tabular}

6 Table 5. Sizing of reactive absorption and distillation columns

\begin{tabular}{|l|c|c|c|}
\hline Parameter & Unit & Reactive absorption & MeOH distillation \\
\hline Packing & - & Katapak SP & Pall 16 mm \\
\hline Pressure, top - bottom & bar & $2.3-2.34$ & $1.2-1.22$ \\
\hline Temperature, top - bottom & ${ }^{\circ} \mathrm{C}$ & $114.8-105.2$ & $67-101$ \\
\hline Theoretical stages/feed & - & 15 & $11 / 7$ \\
\hline Column diameter & $\mathrm{m}$ & 0.42 & $0.40 / 0.32$ \\
\hline HETP & $\mathrm{m}$ & 0.6 & 0.5 \\
\hline Sections & - & 2 & $81 / 80$ \\
\hline Flooding & $\%$ & 82 & 1.2 \\
\hline Holdup & $\mathrm{L}$ & 15 & 4 \\
\hline Height packing / total & $\mathrm{m}$ & 9 & $225 / 115$ \\
\hline Qcond / Qreb & $\mathrm{kW}$ & $0 / 0$ & \\
\hline
\end{tabular}

9 Table 6. FFA reduction by reactive absorption with heterogeneous catalyst

\begin{tabular}{|l|c|c|c|c|c|c|c|}
\hline & & \multicolumn{3}{|c|}{ FFA 10 \%wt in feedstock } & \multicolumn{3}{c|}{ FFA 15 \%wt in feedstock } \\
\hline Flowrate & & Feed & Bottom & Top & Feed & Bottom & Top \\
\hline Triglycerides & $\mathrm{kg} / \mathrm{h}$ & 2,250 & 2,250 & 0 & 2,125 & 2,125 & 0 \\
\hline FFA & $\mathrm{kg} / \mathrm{h}$ & 250 & 10.73 & 0.05 & 375 & 23.71 & 0.07 \\
\hline Ester & $\mathrm{kg} / \mathrm{h}$ & 0 & 255.83 & 0.14 & 0 & 375.64 & 0.17 \\
\hline Methanol & $\mathrm{kg} / \mathrm{h}$ & 500 & 60.10 & 401.64 & 500 & 62.28 & 381.54 \\
\hline Water & $\mathrm{kg} / \mathrm{h}$ & 0 & 0.03 & 21.49 & 0 & 0.05 & 31.54 \\
\hline Total & $\mathrm{kg} / \mathrm{h}$ & 3000 & $2,576.69$ & 423.31 & 3,000 & $2,586.68$ & 413.32 \\
\hline FFA & $\% \mathrm{wt}$ & 10 & 0.42 & & 15 & 0.92 & \\
\hline FFA reduction & $\%$ & & 95.71 & & & 93.68 & \\
\hline
\end{tabular}


2 Table 7. Evolution of mass flow rates of species after reactors (values in $\mathrm{kg} / \mathrm{h}$ )

\begin{tabular}{|l|c|c|c|c|}
\hline & Feed & CSTR & PFR & RD \\
\hline Triglycerides & 2,250 & 1,844 & 413 & 1 \\
\hline FFA & 250 & 2.5 & 2.5 & 2.5 \\
\hline Methanol & 500 & 439 & 283 & 38 \\
\hline FAME & - & 567 & 2,010 & 2,496 \\
\hline Glycerol & - & 50 & 195 & 61 \\
\hline Diglycerides & - & 68 & 36 & 3 \\
\hline Monoglycerides & - & 32 & 63 & 13 \\
\hline Conversion \% & - & 26.2 & 83.5 & 99.9 \\
\hline
\end{tabular}

Table 8. Sizing elements of the reactive distillation and methanol recovery units

\begin{tabular}{|l|c|c|c|}
\hline Parameter & Unit & Reactive distillation & MeOH recovery \\
\hline Packing & - & CY & Pall $25 \mathrm{~mm}$ \\
\hline Pressure, top - bottom & bar & $1.8-1.94$ & $0.3-0.35$ \\
\hline Temperature, top - bottom & ${ }^{\circ} \mathrm{C}$ & $87-142$ & $46-140$ \\
\hline Stages/ feed & - & $14 / 1$ & $12 / 1$ \\
\hline Column diameter & $\mathrm{m}$ & 0.42 & 0.5 \\
\hline HETP & $\mathrm{m}$ & 0.535 & 0.5 \\
\hline Sections & - & 1 & 1 \\
\hline Flooding & $\%$ & 80 & 75 \\
\hline Holdup & litre & $10($ Max. 15.7$)$ & 1.35 \\
\hline Height packing / total & $\mathrm{m}$ & 7.5 & $0 / 245$ \\
\hline Qcond / Qreb & $\mathrm{kW}$ & $200 / 50$ & \\
\hline
\end{tabular}

Table 9. Design parameters of multi-tubular reactors for transesterification by heterogeneous catalysis

\begin{tabular}{|c|c|c|c|c|c|c|}
\hline Reactor & $\begin{array}{c}\text { Tube diameter } \\
D_{t}\end{array}$ & $\begin{array}{c}\text { Length } \\
L\end{array}$ & $\begin{array}{c}\text { Serpentines } \\
N s\end{array}$ & $\begin{array}{c}\text { Volume } \\
V_{R}\end{array}$ & $\begin{array}{c}\text { Residence time } \\
t_{R}\end{array}$ & $\begin{array}{c}\text { Superficial velocity } \\
w_{s}\end{array}$ \\
\hline & $\mathrm{m}$ & $\mathrm{m}$ & - & $\mathrm{m}^{3}$ & $\mathrm{sec}$ & $\mathrm{mm} / \mathrm{s}$ \\
\hline $\mathrm{R}-1$ & 0.3 & 70 & 2 & 9.9 & 3,703 & 18.9 \\
\hline $\mathrm{R}-2$ & 0.3 & 70 & 2 & 9.9 & 4,318 & 15.0 \\
\hline
\end{tabular}


1 Table 10. Economic evaluation comparison of integrated processes for biodiesel production (n.b. abbreviations refer to flowsheets in Figure 4, Figure 7, and Figure 9)

\begin{tabular}{|c|c|c|c|c|c|c|c|c|}
\hline Process 1 & PCE & IC & Process 2 & PCE & IC & Process 3 & PCE & IC \\
\hline Reactors & & & Reactors & & & Reactors & & \\
\hline FFA-RD & 25 & 150 & FFA-GLY & 59 & 119 & FFA-GLY & 59 & 119 \\
\hline CSTR & 64 & 205 & R-1 & 72 & 193 & R-1 & 79 & 203 \\
\hline PFR & 25 & 117 & R-2 & 72 & 192 & & & \\
\hline RDIST & 43 & 238 & & & & & & \\
\hline Total & 157 & 711 & Total & 203 & 504 & Total & 138 & 322 \\
\hline Separators & & & Separators & & & Separators & & \\
\hline D-1 & 18 & 106 & FL-1 & 25 & 106 & FL-1 & 25 & 106 \\
\hline D-2 & 16 & 119 & D-1 & 15 & 97 & D-1 & 15 & 97 \\
\hline \multirow[t]{3}{*}{ DIST } & 69 & 277 & D-2 & 15 & 97 & DIST-BD & 86 & 477 \\
\hline & & & DIST & 72 & 314 & EVAP-1 & 15 & 104 \\
\hline & & & DRYER & 18 & 134 & DRYER & 18 & 134 \\
\hline Total & 103 & 502 & Total & 145 & 748 & Total & 159 & 917 \\
\hline Exchangers & & & Exchangers & & & Exchangers & & \\
\hline COND & 9 & 59 & HX-1 & 11 & 69 & FEHE-1 & 10 & 66 \\
\hline H-3 & 10 & 59 & HX-2 & 11 & 69 & FEHE-2 & 11 & 69 \\
\hline COOL-1 & 10 & 61 & HX-4 & 15 & 83 & HX-1 & 13 & 82 \\
\hline COOL-2 & 10 & 61 & HX-5 & 9 & 66 & HX-2 & 16 & 88 \\
\hline $\mathrm{H}-1$ & 10 & 64 & HX-6 & 13 & 70 & HX-3 & 28 & 128 \\
\hline AC-1 & 10 & 60 & AC-1 & 9 & 59 & HX-4 & 8 & 46 \\
\hline \multirow[t]{4}{*}{$\mathrm{H}-2$} & 13 & 80 & AC-2 & 10 & 61 & HX-5 & 8 & 49 \\
\hline & & & AC-4 & 11 & 62 & AC-1 & 11 & 62 \\
\hline & & & B2 & 13 & 82 & $\mathrm{AC}-2$ & 9 & 59 \\
\hline & & & B4 & 10 & 66 & COOL-1 & 9 & 59 \\
\hline Total & 71 & 443 & & 112 & 688 & Total & 123 & 708 \\
\hline Pumps & & & Pumps & & & Pumps & & \\
\hline \multirow[t]{3}{*}{ P-1 } & & & P-1 & 52 & 80 & P-1 & 52 & 79 \\
\hline & & & $\mathrm{P}-2$ & 52 & 80 & $\mathrm{P}-2$ & 52 & 80 \\
\hline & & & $\mathrm{P}-3$ & 51 & 82 & P-3 & 4 & 32 \\
\hline Total & 4 & 27 & Total & 155 & 242 & Total & 109 & 192 \\
\hline Total costs $(\mathrm{k} \$)$ & 335 & 1,683 & & 614 & 2,181 & & 529 & 2,139 \\
\hline
\end{tabular}

4 Table 11. Key performance indicators for integrated processes for biodiesel production

\begin{tabular}{|l|l|c|c|c|}
\hline KPI & Unit & Process 1 & Process 2 & Process 3 \\
\hline Utility cost & USD/year & 125,162 & 247,980 & 159,461 \\
\hline Utility requirements & $\mathrm{kW}$ & 1,413 & 1,556 & 1,162 \\
\hline Heating duty & $\mathrm{kW}$ & 697 & 827 & 663 \\
\hline Specific energy use & $\mathrm{kWh} / \mathrm{t}$ & 278.8 & 330.8 & 265.2 \\
\hline $\mathrm{CO} 2$ emissions & $\mathrm{kg} / \mathrm{h}$ & 165 & 196 & 183 \\
\hline Specific CO2 emissions & $\mathrm{kg} / \mathrm{t}$ & 66 & 78.4 & 73.2 \\
\hline
\end{tabular}




\section{Figure captions}

4 Figure 1. Block diagram for biodiesel manufacturing from waste lipids

6 Figure 2. FFA esterification with methanol by batch treatment and $\mathrm{H} 2 \mathrm{SO} 4$ catalyst

8 Figure 3. FFA esterification with methanol by reactive absorption

10 Figure 4. Process 1 - FFA esterification with methanol by reactive absorption and 11 transesterification by reactive distillation and homogeneous catalysis

13 Figure 5. Flow rates of glycerides and glycerol in a reactive distillation column 14

15 Figure 6. Variable-time reaction device for liquid-phase catalytic reactions with switching 16 valve system for varying the residence time and easy-change of catalyst

Figure 7. Process 2 - FFA esterification with methanol and transesterification by heterogeneous catalysis

Figure 8. Profiles of glycerides mass fractions along the reactor bed, in the first (left) and 22 second (right) catalytic reactor

Figure 9. Process 3 - FFA esterification, transesterification by heterogeneous catalysis, and 25 vacuum distillation 


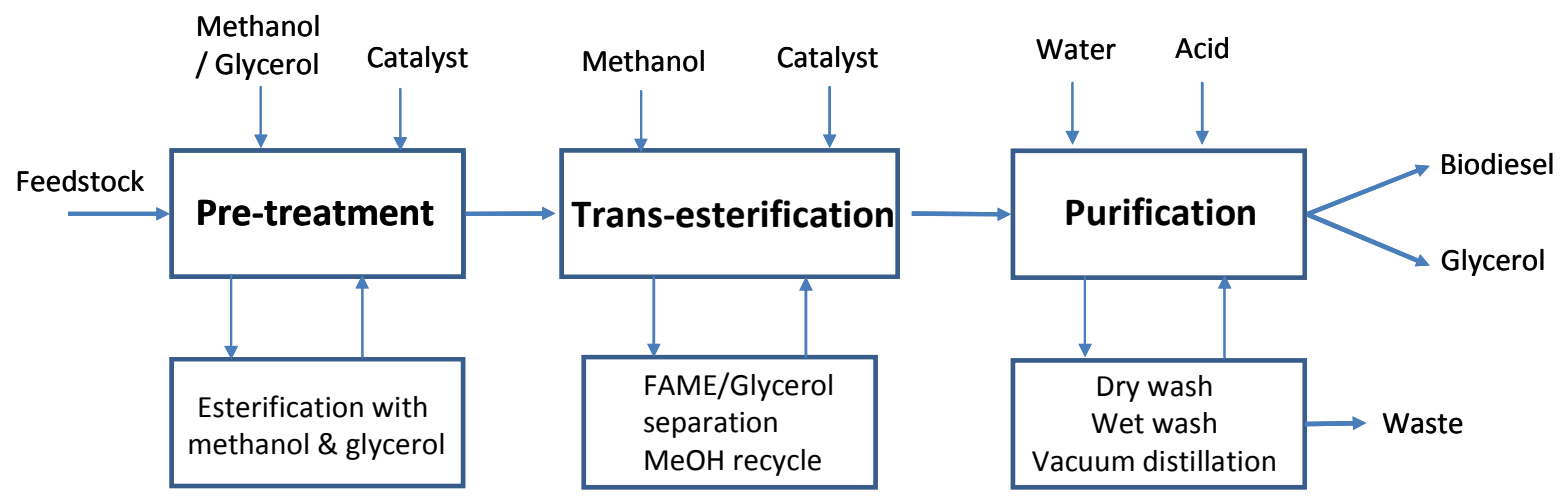

Figure 1. Block diagram for biodiesel manufacturing from waste lipids

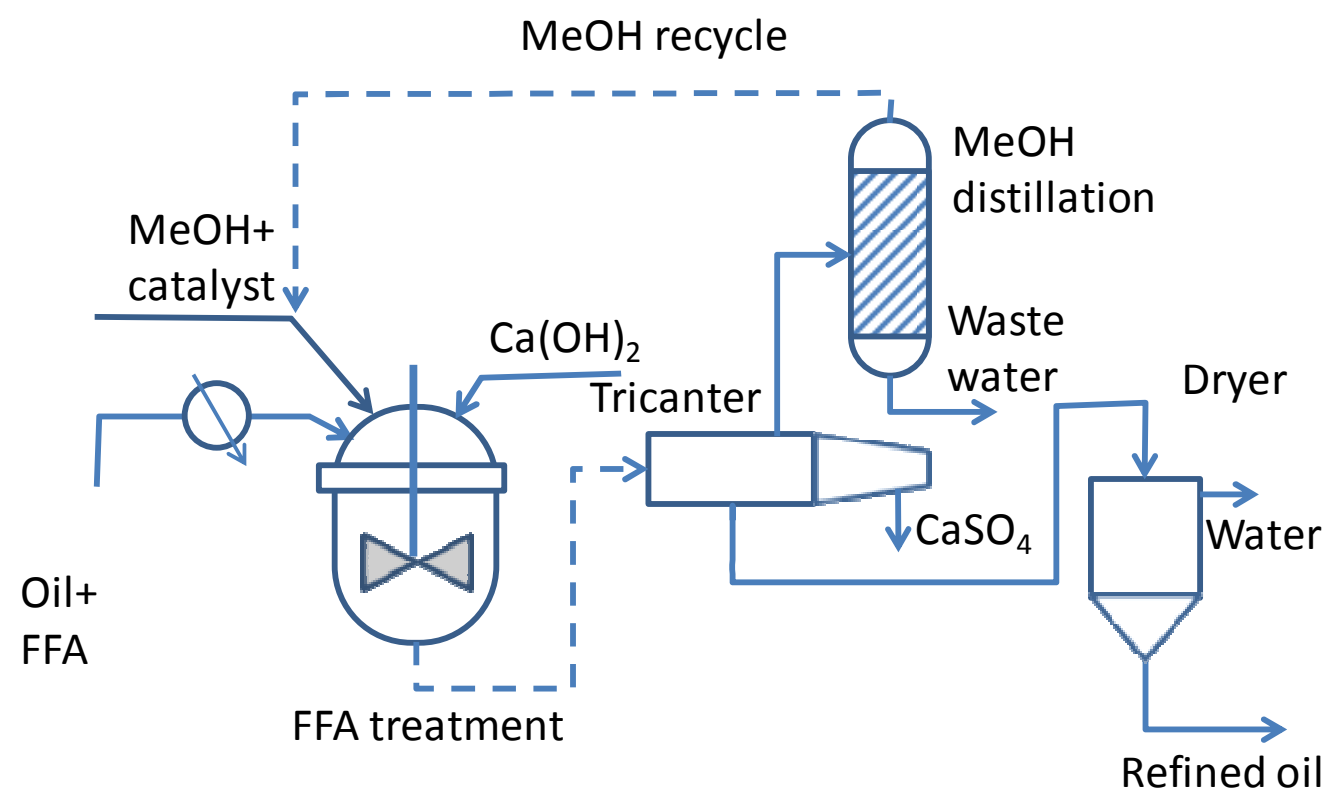

10 


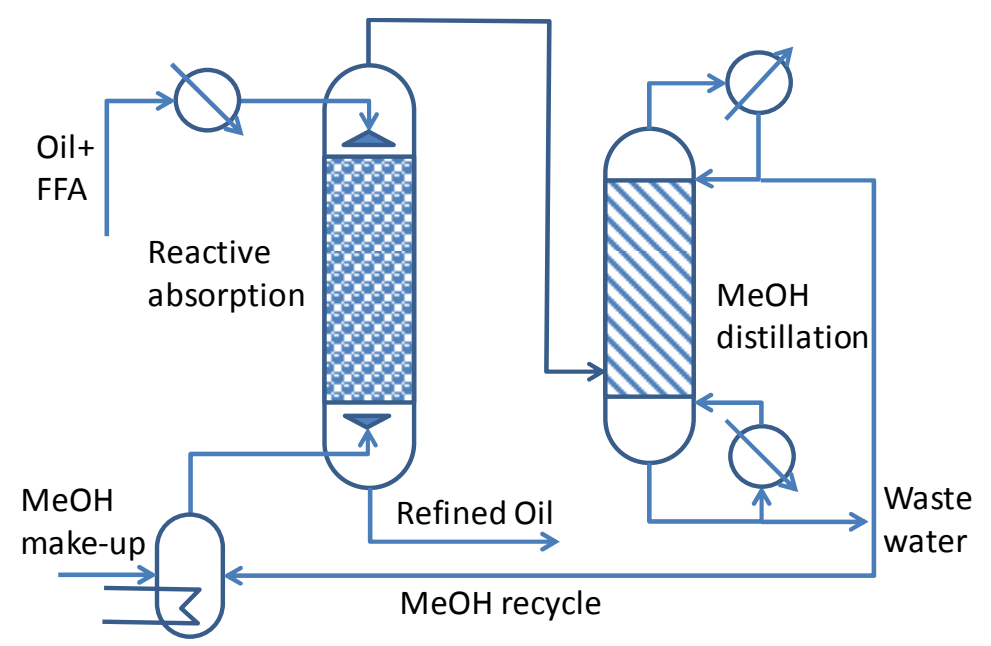

Figure 3. FFA esterification with methanol by reactive absorption

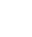

(1)

(1)

8

0

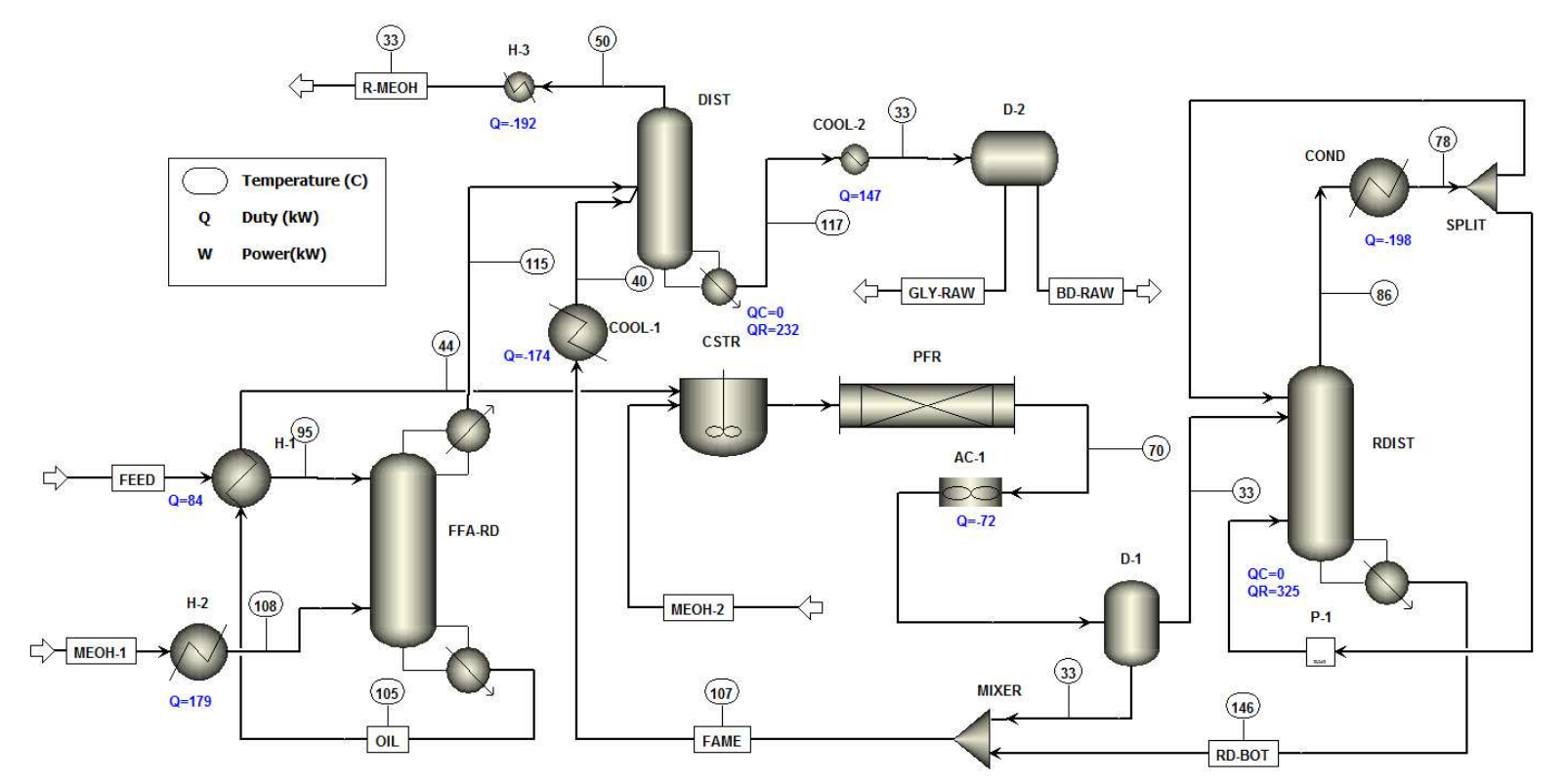

Figure 4. Process 1 - FFA esterification with methanol by reactive absorption and transesterification by reactive distillation and homogeneous catalysis 


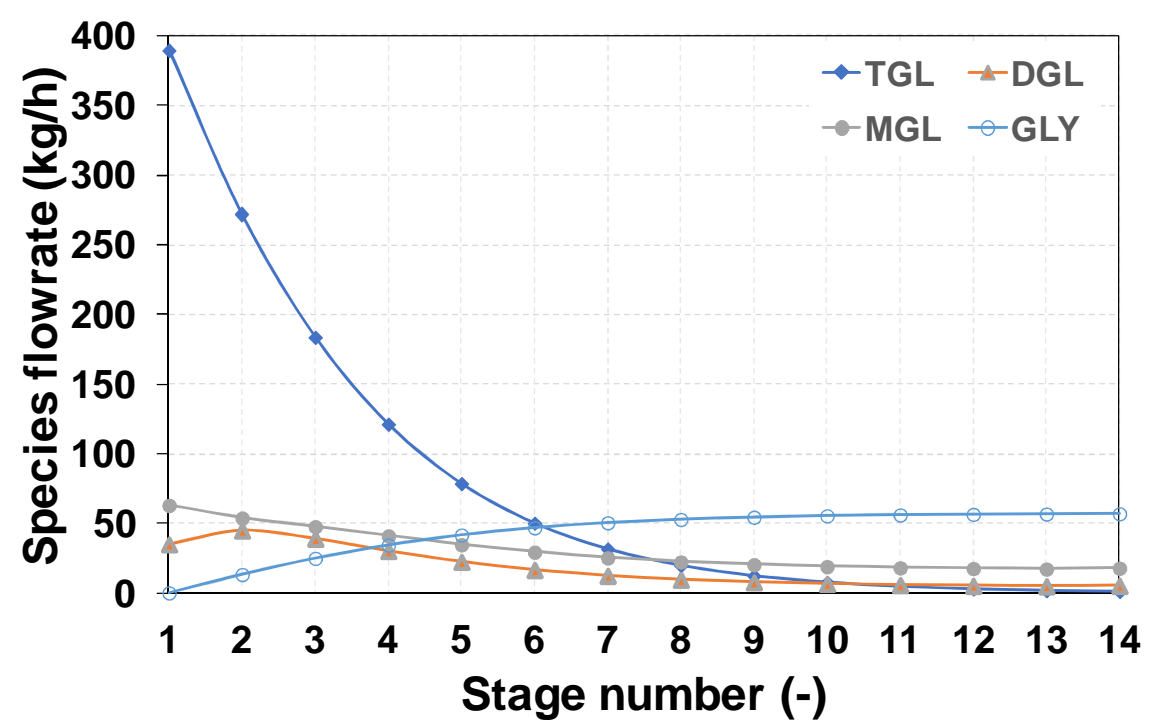

Figure 5. Flow rates of glycerides and glycerol in a reactive distillation column

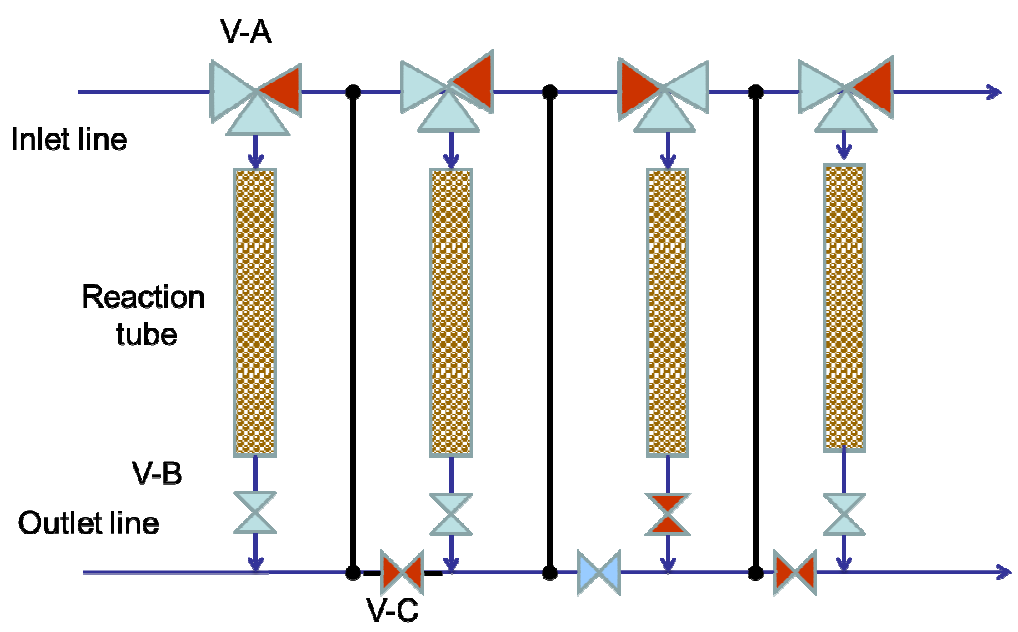
valve system for varying the residence time and easy-change of catalyst 


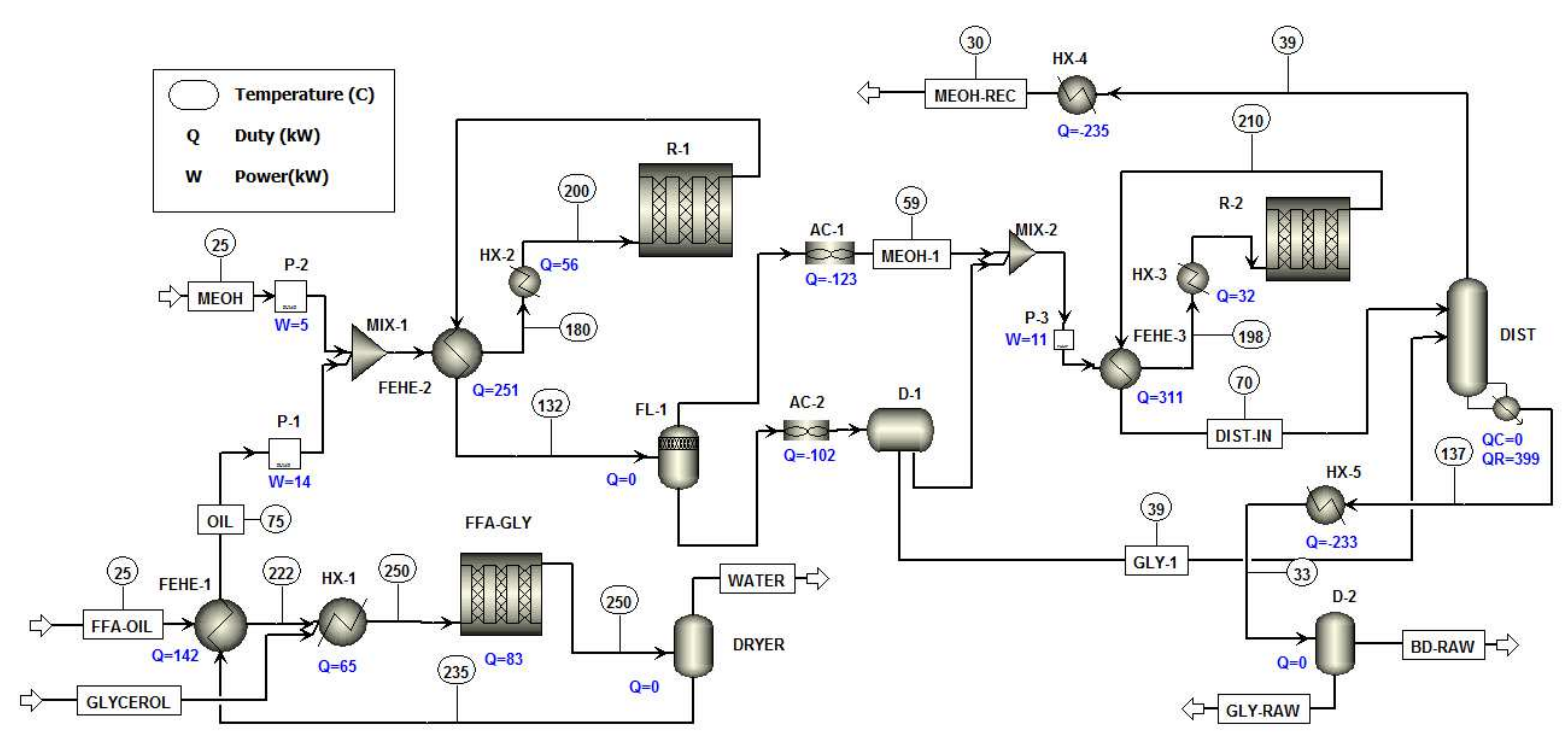

Figure 7. Process 2 - FFA esterification with methanol and transesterification by heterogeneous catalysis
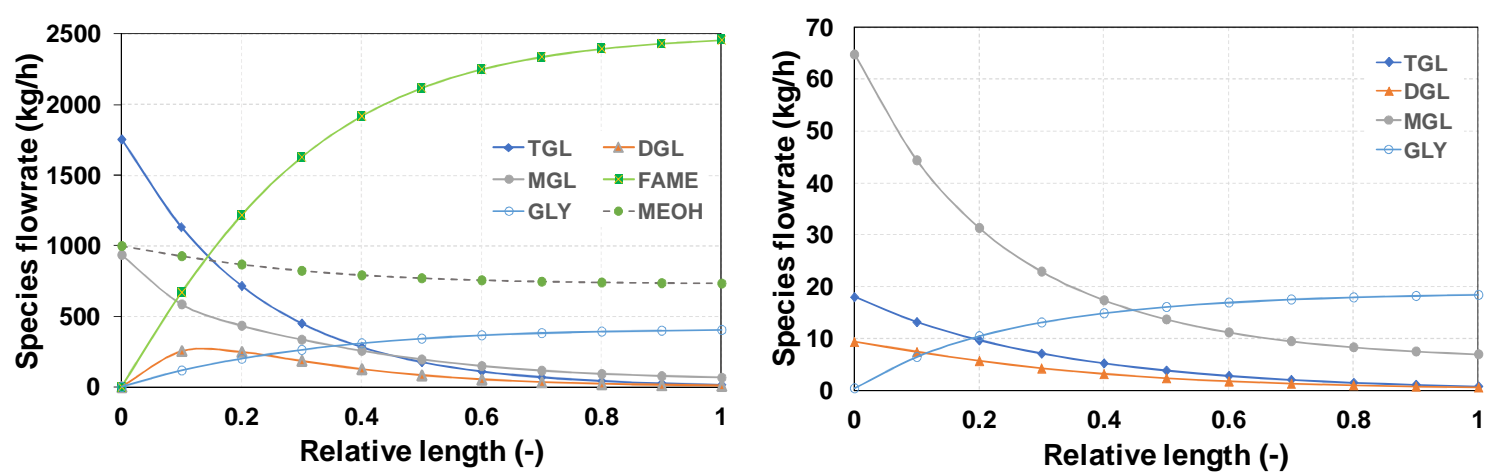

Figure 8. Profiles of glycerides mass fractions along the reactor bed, in the first (left) and second (right) catalytic reactor 
1

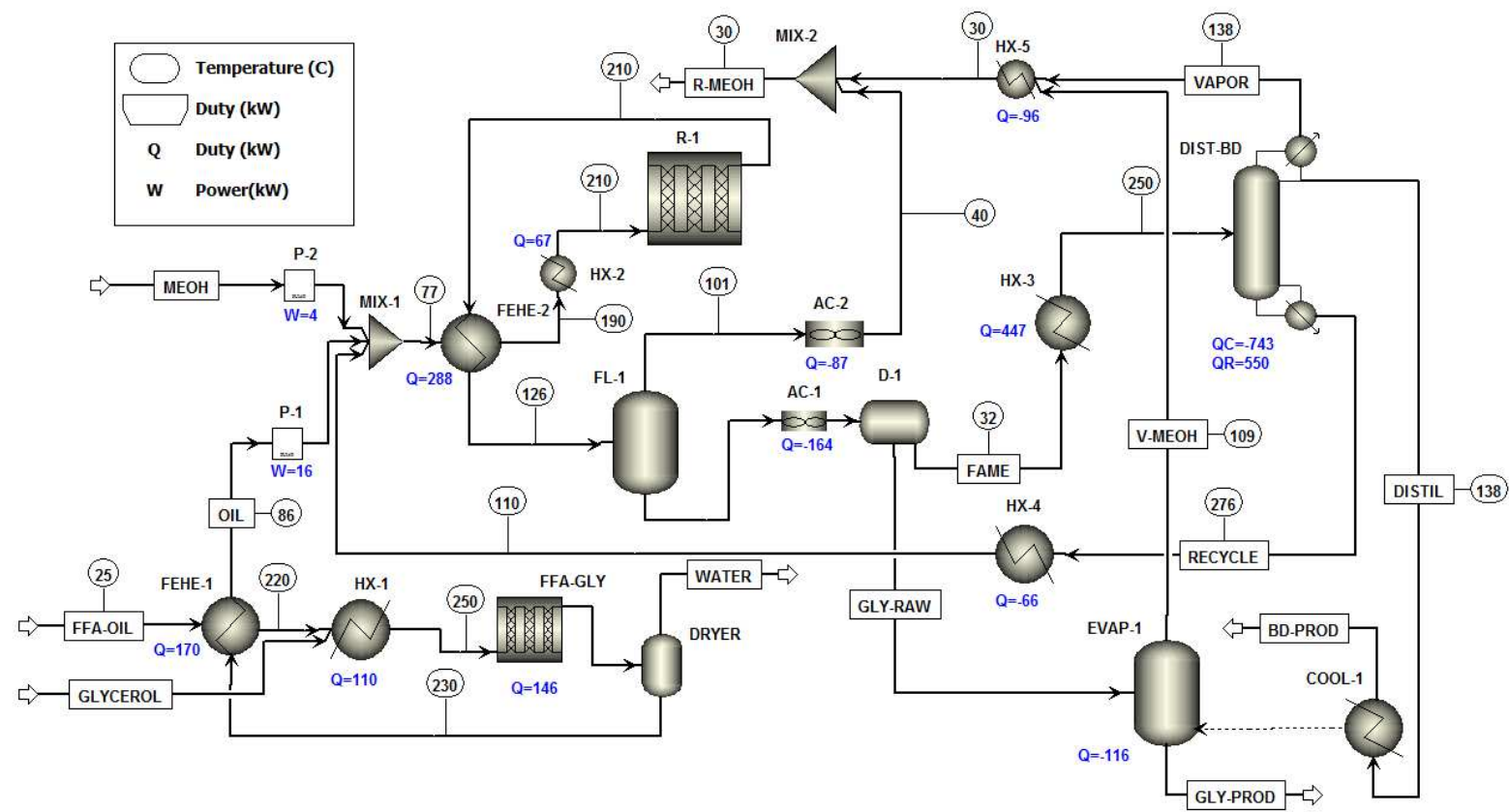

Figure 9. Process 3 - FFA esterification, transesterification by heterogeneous catalysis, and 4 vacuum distillation of the FAME 
1 Graphical abstract

2

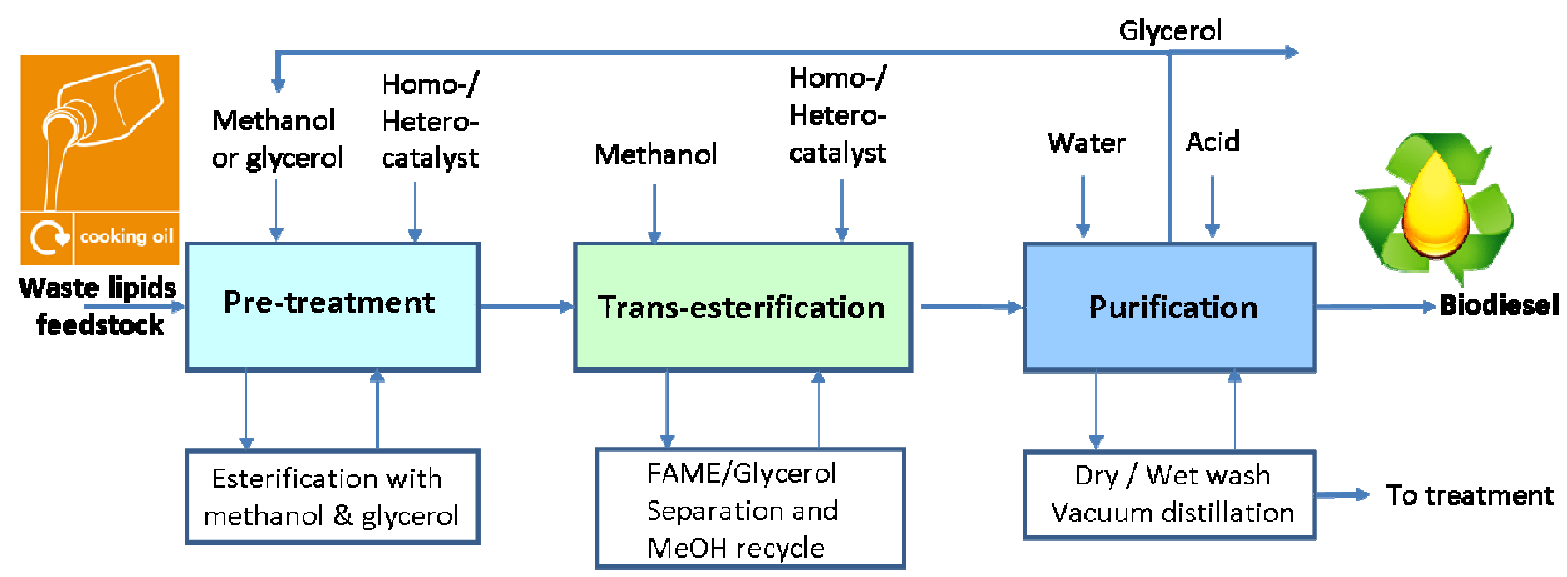

